\title{
The comparative and degree pluralities
}

\author{
Jakub Dotlačil ${ }^{1}$ • Rick Nouwen ${ }^{2}$
}

Published online: 15 December 2015

(C) The Author(s) 2015. This article is published with open access at Springerlink.com

\begin{abstract}
Quantifiers in phrasal and clausal comparatives often seem to take distributive scope in the matrix clause: for instance, the sentence John is taller than every girl $i s$ is true iff for every girl it holds that John is taller than that girl. Broadly speaking, two approaches exist that derive this reading without postulating the (problematic) wide scope of the quantifier: the negation analysis and the interval analysis of thanclauses. We propose a modification of the interval analysis in which than-clauses are not treated as degree intervals but as degree pluralities. This small change has significant consequences: it yields a straightforward account of differentials in comparatives and it correctly predicts the existence of hitherto unnoticed readings, viz. cumulative readings of clausal comparatives. Finally, this paper also makes the case that using degree pluralities is conceptually appealing: it allows us to restrict the analysis of comparatives by mechanisms that are postulated independently in the semantics of pluralities.
\end{abstract}

\section{Introduction}

It is probably a universal property of language that it allows us to talk about single individuals as well as pluralities formed from them. Thanks to this property, we don't have to restrict our discussions to Mary or the table over there; instead, we can ascribe properties to pluralities, say, Mary, Sue, and John or the tables and chairs. The

Jakub Dotlačil

j.dotlacil@gmail.com

1 Center for Language and Cognition, University of Groningen, Oude Kijk in't Jatstraat 26, NL-9712 EK Groningen, The Netherlands

2 Department of Languages, Literature and Communication, Utrecht University, Trans 10, NL-3512 JK Utrecht, The Netherlands 
semantic literature that studies pluralities often postulates the existence of entities that are non-atomic in nature, whether these be implemented in terms of sets (e.g. Hoeksema 1983, Gillon 1987, Schwarzschild 1996, Winter 2002) or algebraic sums/joins (e.g. Link 1983, Krifka 1989, Landman 1989, 1996, 2000). In addition, the literature has recognised the semantic mechanisms that govern the relations such pluralities engage in. For instance, (1) below can be read in various ways. A distributive reading says that both women separately wrote twelve books (i.e. twenty-four in total). A collective reading says that Mary and Sue collaborated on a total of twelve books. Finally, a cumulative reading says that there is a total of twelve books written by either Mary or Sue, where some were written by Mary and some were written by Sue. On top of postulating sum (or set) denotations for Mary and Sue and twelve books, the semantics for (1) will thus need to provide various ways in which these sums enter into the write relation.

Mary and Sue wrote twelve books.

There is a good case to be made that plural individuals and semantic mechanisms that operate on plural structures are domain-independent and, consequently, the postulation of pluralities is not limited to the domain of entities. In the literature, one can find arguments for plural events (Krifka 1989; Schein 1993; Landman 2000; Kratzer 2003), plural information states (van den Berg 1996; Krifka 1996; Nouwen 2003, 2007; Brasoveanu 2008), plural times (Artstein and Francez 2003), and plural propositions (Beck and Sharvit 2002). Missing from this list are plural degrees. Although degree pluralities do make an appearance in a handful of places (Matushansky and Ruys 2006; Fitzgibbons et al. 2008; Beck 2012), as far as we know there has so far been no dedicated argument in the literature in favour of a parallel between the semantic structures available for entities and those available for degrees. In this paper, we will provide a motivation for a framework of degree pluralities. Up to a certain extent our rationale is simple. Degrees behave very much like entities and, so, they will partake in exactly the kind of semantic structures as entities do. For instance, (2) clearly has a cumulative reading, where John is 20 years old, Peter is 22, and Mary is 26. (The distributive reading would be non-sensical since it requires each of the three men to have multiple ages.)

\section{(2) John, Peter, and Mary are 20, 22, and 26 years old.}

Any analysis of this example will have to resort to a cumulative relation between two pluralities: on the one hand the plural entity consisting of John, Peter, and Mary, and on the other hand the degree sum consisting of 20, 22, and 26 years. In other words, sentences like (2) already seem to commit the semanticist to the assumption that, like the domain of entities, the domain of degrees contains both atoms and sums.

Our claims go further than this resemblance between entity and degree ontology. The force of our proposal will rest in the semantics of the comparative. We put forward an approach where the comparative is interpreted as a relation between degree pluralities, which entails that the comparative can be read both distributively and cumulatively. We will support our proposal for a plural comparative in two distinct ways. On the one hand, we will provide data that suggest a necessarily plural (i.e. cumulative) 
interpretation of the relation between degrees expressed by comparative morphology. On the other hand, we will show that the plural degree framework allows for a reinterpretation of existing interval-based theories of degree morphology. Replacing intervals with pluralities will give a more natural analysis of quantifiers in than-clauses and it also solves a hitherto open problem concerning differentials.

In the semantic literature on the comparative, the interpretation of than-clauses takes a central role, and it equally does so in this paper. We start in the next section with an introduction to the issues central to comparative degree semantics and the semantics of than-clauses. We also give a sneak preview to our take on these issues (Sects. 2 and 3). After that, we postulate a simple framework for plural degree semantics (Sect. 4). We show that a plural degree semantics can relatively straightforwardly handle the crucial issues of comparative degree semantics, including the interplay of comparatives with differentials, which poses a challenge to all existing semantic theories (Sect. 5). Furthermore, plural degree semantics predicts a reading that has so far played hardly any role in the discussion of comparatives. We call that reading a cumulative comparison and argue that it strongly supports our analysis (Sect. 6). Section 7 discusses open issues.

Before we start, we should add that Sigrid Beck has independently developed an account of quantified than-clauses that is in some ways similar to ours (Beck 2014). This is not very surprising, since, as will become clear, our own approach leans heavily on Beck's earlier work. We will offer a comparison to Beck (2014) along the way.

\section{Background: quantifiers in than-clauses}

At least since von Stechow (1984), semanticists have used quantifiers in than-clauses as a testing ground to find the correct interpretation of comparatives. We illustrate this point by discussing two types of approaches to the comparative, which we will call, following previous literature, the negation and the interval approach respectively. Our starting point is the interpretation that the two approaches would assign to a run-of-themill case of comparison, (3), shown in (3a) and (3b). Before we proceed to discussing this example, one warning to the reader: our semantics captures the essence of the two approaches, but it glosses over a lot of detail and does not show the many varieties that exist in both approaches. The same is not only true for (3), but for the rest of this section as well. We introduce these simplifications to make a general point about the empirical prospects of either approach, regardless of the details of their implementation.

John is taller than Mary (is).

a. $\exists d[\operatorname{tall}(j, d) \wedge \neg \operatorname{tall}(m, d)]$

b. $\max (\lambda d \operatorname{dall}(j, d))>\max (\lambda d \operatorname{dall}(m, d))$

negation approach interval approach

(3a) and (3b) share the assumption that adjectives express monotone relations between individuals and degrees. The monotonicity lies in the fact that if John's height corresponds to $d_{j}$, then not only is John tall to degree $d_{j}$ (i.e. $\operatorname{tall}\left(j, d_{j}\right)$ is true), but John is also tall to any lower degree $d<d_{j}$. The monotonicity is explicitly expressed by assuming (4) as the interpretation of tall (and similarly for other gradable adjectives). 
Here, we use $\mu$ as the relevant measure function for the adjective. In this case, $\mu(x)$ returns $x$ 's height. So for example in $(3 \mathrm{~b}), \lambda d \operatorname{tall}(j, d)$ corresponds to the interval (0,John's height].

$$
\llbracket \operatorname{tall} \rrbracket=\lambda d \lambda x \cdot \mu(x) \geq d
$$

Coupled with the monotonicity assumption, (3a) looks at the complement of Mary's interval of height, (Mary's height, $\infty)$, and says that this overlaps with ( 0 , John's height]. (3b) states that $\max (0$, John's height] $>\max (0$, Mary's height), i.e., John's height $>$ Mary's height.

In their basic forms, both approaches make surprisingly problematic predictions once we turn to apparently simple examples that have a universal quantifier in the than-clause, as in (5).

(5) John is taller than every girl is.
a. $\exists d[\operatorname{tall}(j, d) \wedge \neg \forall x[\operatorname{girl}(x) \rightarrow \operatorname{tall}(x, d)]]$
b. $\max (\lambda d \cdot \operatorname{tall}(j, d))>\max (\lambda d . \forall x[\operatorname{girl}(x) \rightarrow \operatorname{tall}(x, d)])$

Both (5a) and (5b) express that John is taller than the shortest girl. The required reading is much stronger, namely that John's height exceeds that of the tallest girl. What is striking is that this stronger reading can be obtained if we assume that the quantifier every girl takes wide scope (von Stechow 1984).

$$
\begin{aligned}
& \text { a. } \forall x[\operatorname{girl}(x) \rightarrow \exists d[\operatorname{tall}(j, d) \wedge \neg \operatorname{tall}(x, d)]] \\
& \text { b. } \forall x[\operatorname{girl}(x) \rightarrow \max (\lambda d \cdot \operatorname{tall}(j, d))>\max (\lambda d \cdot \operatorname{tall}(x, d))]
\end{aligned}
$$

An analysis along the lines of (6) is an unlikely solution, however, given that it is generally assumed that quantifier raising is clause-bound (May 1985; Reinhart 1997), which means that we would have obtained (6a) and (6b) via an island violation. In the past decade or so, developments of the two approaches have avoided the need to resort to such violations by assuming that the relevant scope relation is located within the than-clause. This is most easily illustrated using the negation approach, which often postulates that at some level of description the than-clause contains an actual negation operator (Gajewski 2008; van Rooij 2008; Schwarzschild 2008). In our simplified setup, than every girl is could be represented as follows (assuming that the ellipsis is recovered in interpretation):

$$
\text { [ than [ NOT [ [ every girl ] [ is [ tall ] ] ] ] ] }
$$

Such a setup makes it possible for the quantifier every girl to get scope over negation:

$$
\text { [ than [ [ every girl ] } 1 \text { NOT }\left[t_{1}[\text { is [ tall ] ] ] ] ] }\right.
$$

Following standard assumptions, this would give us the term $\lambda d . \forall x[\operatorname{girl}(x) \rightarrow$ $\neg \operatorname{tall}(x, d)]$, which corresponds to the interval that extends upwards from just above the tallest girl's height. The whole construction John is taller than every girl is can now be interpreted as saying that there exists a degree in that interval to which John is tall. In other words, John is taller than the tallest girl. 
Although this derives the desired interpretation, there are some interesting and serious problems with this view. Most importantly, if (8) has come about by quantifierraising the subject, then we would expect to see ambiguity, or at least we would like to have some rationale for why universal quantifiers always seem to take wide scope with respect to negation. ${ }^{1}$ Worse, one would have to explain why constructions that normally do not display movement are necessarily interpreted in a high position, whereas others are not. For instance, for (9) only the low negation reading is available, whilst for (10) only the high negation reading is found.

(9) John is taller than Bill and Peter.

$$
\text { a. } \exists d[\operatorname{tall}(j, d) \wedge \neg(\operatorname{tall}(b, d) \wedge \operatorname{tall}(p, d))]
$$

b. $\exists d[\operatorname{tall}(j, d) \wedge(\neg \operatorname{tall}(b, d) \wedge \neg \operatorname{tall}(p, d))]$

unavailable available

(10) John is taller than Bill or Peter.

$$
\begin{aligned}
& \text { a. } \exists d[\operatorname{tall}(j, d) \wedge \neg(\operatorname{tall}(b, d) \vee \operatorname{tall}(p, d))] \\
& \text { b. } \exists d[\operatorname{tall}(j, d) \wedge(\neg \operatorname{tall}(b, d) \vee \neg \operatorname{tall}(p, d))]
\end{aligned}
$$

available unavailable

As we will see below, the fact that no actual ambiguity is observed is motivation for Beck (2010) to aim for an analysis that involves a fixed scope relation for all thanclauses. Before we turn to such ways of improving on the basic interval and negation approach, we would like to mention another aspect that makes these approaches problematic.

The issue we sketched above is that the two standard approaches predict a morethan-minimum reading rather than the required more-than-maximum reading for thanclauses with a universal quantifier. In general, comparatives always seem to provide the latter rather than the former reading (but see below). For instance, (9) and (10) are synonymous - they both mean that John is taller than whoever is tallest amongst Bill and Peter. One could think, then, that the mechanism we are after is simply one which returns the maximum degree of all the individuals in the domain of quantification in the than-clause, independent of the quantifier relation that is involved. Such a mechanism, however, would be too simple for the case of differentials, where the desired readings are a bit trickier still. Consider (11).

(11) John is exactly 3 inches taller than every girl.

As before, the correct interpretation for (11) can be paraphrased by giving the quantifier wide scope, as in (12).

(12) Every girl is such that John is exactly 3 inches taller than her.

Not only does (11) say that John is exactly 3 inches taller than the tallest girl; it requires John to be exactly 3 inches taller than any of the other girls too. In other words, (11) entails that all the girls are of the same height.

The issue is that nothing in either the negation or the interval approach allows us to refer to the individual heights of the entities in the domain of quantification. Take

\footnotetext{
1 van Rooij (2008) proposes such a rationale, using the Strongest Meaning Hypothesis of Dalrymple et al. (1998). But see Sect. 2.3.3 of Beck (2010) for problems with this line of avoiding ambiguity.
} 
the form in (8), for instance, which provided the correct interpretation for a regular comparative by letting the than-clause denote $\lambda d . \forall x[\operatorname{girl}(x) \rightarrow \neg \operatorname{tall}(x, d)]$. As we said above, this is an interval extending upward from the tallest girl's height. Crucially, this interval does not contain the heights of any of the girls and, so, there is no way the ultimate truth conditions are going to include the entailment that the girls are all equally tall.

For the interval strategy, a way may have been found to associate than every girl is with the interval (0,the tallest girl's height]. For example, Schwarzschild and Wilkinson (2002) represent a case of an interval strategy which can derive the correct interpretation of comparatives with differentials. However, accounting for differentials in the interval strategy is commonly done by stipulating extra conditions on comparative clauses that are not needed otherwise, be these conditions on sub-intervals (Schwarzschild and Wilkinson 2002), LFs (Heim 2006), or scale granularity (Beck 2010) (see Fleisher, to appear, for details). Our goal is to solve the puzzle of quantifiers in than-clauses in such a way that the solution automatically yields an appropriate semantics of differentials. We do so by reinterpreting modern versions of the interval strategy, in particular that of Beck (2010), to which we turn now.

\section{Beck's selection approach}

The main innovation in Beck (2010) is, we believe, to assume that standard clauses involve a selection mechanism akin to the one found in the semantics of definite descriptions or questions. Her analysis is based on a variation of what we called the interval strategy that is due to Schwarzschild and Wilkinson (2002) and Heim (2006). In this approach, than-clauses are lifted to express sets of intervals, rather than simply intervals. To illustrate the strength of the approach, it suffices to assume that intervals are introduced at the level of the adjective as in (13), but see Beck (2010) and especially Heim (2006) for alternative possibilities.

$$
\llbracket \text { tall } \rrbracket=\lambda D_{\langle d, t\rangle} \cdot \lambda x_{e} \cdot \mu(x) \in D
$$

The combination of (13) with the semantics of quantifiers and the abstraction over intervals leads to the following meaning for than-clauses of the form than $Q$ is/are tall.

$$
\lambda D \cdot Q(\lambda x \cdot \mu(x) \in D)
$$

For a non-quantificational than-clause like than Bill is tall this yields all the sets of degrees that contain Bill's height. For than every girl is tall it gives all the sets of degrees that contain the height of every girl. Beck now assumes that the final denotation of the than-clause comes about in two steps:

(15) Step 1-Select the most informative sets in the set of sets of degrees

Step 2-Select the highest degree out of these most informative sets

Step 1 is implemented by defining a function $\min$ that picks those sets from a collection of sets that do not contain subsets that are themselves a member of the collection, and combines these into a single new set: 


$$
\min (\mathcal{D})=\cup \lambda D . D \in \mathcal{D} \wedge \neg \exists D^{\prime}\left[D^{\prime} \in \mathcal{D} \wedge D^{\prime} \subset D\right]
$$

Step 2 is now a regular maximality operator that picks the highest value from the set $\min (\mathcal{D})$. Thus, the two steps select the maximal point of all the minimal interval(s). The results of this selection procedure are illustrated with the following examples: ${ }^{2}$
a. 【than Bill is tall $\rrbracket=\{D \mid D$ contains Bill's height $\}$
b. $\min (\llbracket$ than Bill is tall $\rrbracket)=\{$ Bill's height $\}$
c. $\max (\min (\llbracket$ than Bill is tall $\rrbracket)=$ Bill's height

a. 【than every girl is tall $\rrbracket=\{D \mid D$ contains the heights of each girl $\}$

b. $\min (\llbracket$ than every girl is tall $\rrbracket)=$ the set containing the height of the shortest girl, the height of the tallest girl, and all the degrees in between

c. $\max (\min (\llbracket$ than every girl is tall $\rrbracket))=$ the height of the tallest girl

a. 【than Bill and Peter are tall $\rrbracket=\{D \mid D$ contains both Bill's and Peter's height

b. $\min (\llbracket$ than Bill and Peter are tall $\rrbracket)=$ the set containing Bill's height, Peter's height, and all the degrees in between

c. $\max (\min (\llbracket$ than Bill and Peter are tall $\rrbracket))=$ the height of whoever is tallest from Bill and Peter

a. 【than Bill or Peter are tall $\rrbracket=\{D \mid D$ contains Bill's height or Peter's height or both\}

b. $\min (\llbracket$ than Bill or Peter are tall $\rrbracket)=$ the set containing just Bill's height and Peter's

c. $\max (\min (\llbracket$ than Bill or Peter are tall $\rrbracket))=$ the height of whoever is tallest from Bill and Peter

All these calculations yield the correct result. Below, in Sect. 7, we will look at some further details of this selection mechanism and turn to cases where the result is less clearly favourable. For now, however, let us focus on the merits of Beck's theory. Via the selection mechanism, Beck has done away with any scope ambiguity, making clear predictions as to which reading surfaces where. In the following section we will build further on Beck's approach. Before we do so, we need to point out an important aspect of her selection mechanism.

The selection procedure we discussed above is two-tiered. This allows than-clauses, which are originally assigned type $\langle\langle d, t\rangle, t\rangle$, to yield the degree (type $d$ ) to which the matrix-clause degree is compared. In this way, Beck's analysis is a combination of the approaches operating with sets of intervals and the interval approaches: the composition inside the than-clause is done along the lines of the former accounts,

\footnotetext{
2 To understand the derivations, it helps to keep in mind that $D$ is an interval (if two points $a$ and $b$ are in $D$, then all points between $a$ and $b$ are in $D$, too). In contrast, the set created by the application of $\min$ is just a set of points and does not need to satisfy the mentioned condition. The restriction of $D$ to intervals is commonly held in the interval strategy (see Schwarzschild and Wilkinson 2002, Beck 2010). Heim (2006) takes $D$ to be just a set of points (degrees), but for her this choice is merely a matter of simplicity (sets are in a way more primitive than intervals) and, as she acknowledges, it is not empirically driven. To preview our own account, we will argue that there are empirical reasons to think that than-clauses involve non-dense sets (or rather, pluralities) of degrees.
} 
while the final object is just a single degree, as in the latter accounts. Beck sees this as an advantage because, in her words, "it remains a strength [of the interval approaches] that degree operators combine directly with expressions referring to degrees, and that differentials in particular [as in John is 2 inches taller than Bill is] can be accounted for in a direct and straightforward way" (Beck 2010, p. 27). We agree with Beck that differentials are far from straightforward in the approaches working with sets of intervals and they are particularly problematic for negation accounts. However, we disagree with her conjecture that than-clauses should therefore yield one degree. As we remarked above, differentials like (21) entail that all the girls have the same height. If the than-clause expresses a single degree (say, that of the tallest girl's height) there is no hope of deriving this entailment.

John is exactly 2 inches taller than every girl.

In the next section, we will develop an analysis of than-clauses within a framework of degree pluralities. We will argue that this approach simplifies the selection mechanism to a single operation (since there is no longer any need for than-clauses to yield a single degree), yet it can straightforwardly deal with differentials. Crucially, all this can be achieved with the standard machinery of the semantics of pluralities.

\section{A framework for degree pluralities}

We would now like to propose a minimal variation on theories operating with sets of intervals, one which incorporates a notion of degree plurality. As we will argue in the sections below, the shift from an interval theory to an analysis revolving around plurals improves the empirical coverage.

The idea is, first of all, to extend the domain of degrees to contain degree sums, in addition to degree atoms. For the domain of entities it is standard to assume that it has the structure of the powerset of the domain of atomic entities, with the empty set removed. One can see this as the requirement that the domain be closed under sum formation: it is the smallest set that contains all the atoms and all possible sums that can be formed using these atoms (Link 1983, Landman 1996; see Nouwen 2015 for an overview of plural semantic frameworks). Some useful notions borrowed from the literature on plurality:

(22) a. We will use $a \sqcup b$ (the sum of $a$ and $b$ ) to represent the plural individual that has $a$ and $b$ as its parts.

b. We will use $*$ to represent closure under sum of a set, and we will refer to this as predicate cumulation: $* X:=$ the smallest set such that $* X \supseteq X$ and $\forall x, y \in * X[x \sqcup y \in * X]$.

c. We will use $* *$ to represent closure under sum of a binary relation, and we will refer to this as relation cumulation: ${ }^{* *} R:=$ the smallest set such that $* * R \supseteq R$ and $\forall x, x^{\prime}, y, y^{\prime}\left[\left\langle x, x^{\prime}\right\rangle,\left\langle y, y^{\prime}\right\rangle \in * * R \rightarrow\left\langle x \sqcup y, x^{\prime} \sqcup y^{\prime}\right\rangle \in\right.$ $* * R]$.

d. We will use $\sqsubseteq$ as the part-of relation: $a \sqsubseteq b: \Leftrightarrow a \sqcup b=b$.

e. We will use Atom to return the atoms in a set of pluralities: $\operatorname{Atom}(X):=$ $\lambda x . X(x) \wedge \neg \exists y[y \sqsubseteq x]$. 
For the domain of degrees $\mathcal{D}$, we now make exactly the same assumptions. $\mathcal{D}$ contains all the atomic degrees, as well as all the sums you can form on the basis of those. And it contains nothing else.

Atomic degrees are scalar in nature. This scale, however, is still only defined on atoms: $S=\langle\operatorname{Atom}(\mathcal{D}),>\rangle$. So, if $d$ and $d^{\prime}$ are in $\mathcal{D}$ we can only guarantee that $d>d^{\prime}$ makes sense if both $d$ and $d^{\prime}$ are atomic. That is, a statement like $a \sqcup b>c$ is undefined. Nevertheless, in parallel to the mechanisms we use in the nominal domain, we can form a plural version of $>$ by using the double star operator. Let us illustrate how this works with the following example. Say that both $x>z$ and $y>z$ and both $z>v$ and $z>w$. In that case, $x \sqcup y^{* *}>z$ and $z^{* *}>v \sqcup w$, but also $x \sqcup y^{* *}>v \sqcup w$. Slightly less straightforwardly, if we have a linear order $w>x>y>z$, then $w \sqcup y * *>x \sqcup z$, since for each part in $w \sqcup y$ there is a part in $x \sqcup z$ that is lower in the ranking, and for each part in $x \sqcup z$ there is a part in $w \sqcup y$ that is higher in the ranking. In this way, $>$ is parallel to many, if not all, lexical predicates applying to entities, which are commonly treated as partial functions, applicable to atoms only, unless they are pluralized (Landman 1989; Kratzer 2003).

We propose that adjectives are interpreted as relations between degree pluralities and entities. So rather than (13) (repeated here), we assume (23):

$$
\begin{aligned}
& \llbracket \text { tall } \rrbracket=\lambda D_{\langle d, t\rangle} \cdot \lambda x_{e} \cdot \mu(x) \in D \\
& \llbracket \text { tall } \rrbracket=\lambda d_{d} \cdot \lambda x_{e} \cdot \mu(x) \sqsubseteq d
\end{aligned}
$$

In other words, tall relates individuals to all the degree pluralities that have the individual's height as an atomic part. This creates spuriously large pluralities and, in parallel to Beck's analysis, sets of degree pluralities will have to be reduced to more informative subsets. We do this by defining a minimality operator that operates on pluralities. Whereas Beck proposes (16) (repeated here), we propose (24).

$$
\begin{aligned}
& \min \left(\mathcal{D}_{\langle\langle d, t\rangle, t\rangle}\right)=\cup \lambda D . D \in \mathcal{D} \wedge \neg \exists D^{\prime}\left[D^{\prime} \in \mathcal{D} \wedge D^{\prime} \subset D\right] \\
& \min \left(D_{\langle d, t\rangle}\right)=\iota d . d \in D \wedge \neg \exists d^{\prime}\left[d^{\prime} \in D \wedge d^{\prime} \sqsubset d\right]
\end{aligned}
$$

It should be clear that we are simply implementing ideas of interval approaches within a framework in which intervals have been replaced by pluralities. There are, however, some interesting nuances that differ, as we will show shortly. First, however, let us illustrate how the plural framework works by focusing on the simplest example that we discussed above. We will also use this opportunity to be as specific as possible about all the steps in the analysis, which should make it easier to understand more complex examples as we proceed.

John is taller than Bill is.

We assume, as is standard, that the adjective tall is elided in the than-clause and will be recovered in interpretation.

The semantically annotated syntactic structure for (25) is given in Figure 1. We assume that the comparative morpheme forms a constituent with its adjective, although we are aware of the fact that two traditions exist. One postulates the same constituency in this respect as we do (Larson 1988; Kennedy 1997, 2002; Alrenga and Kennedy 


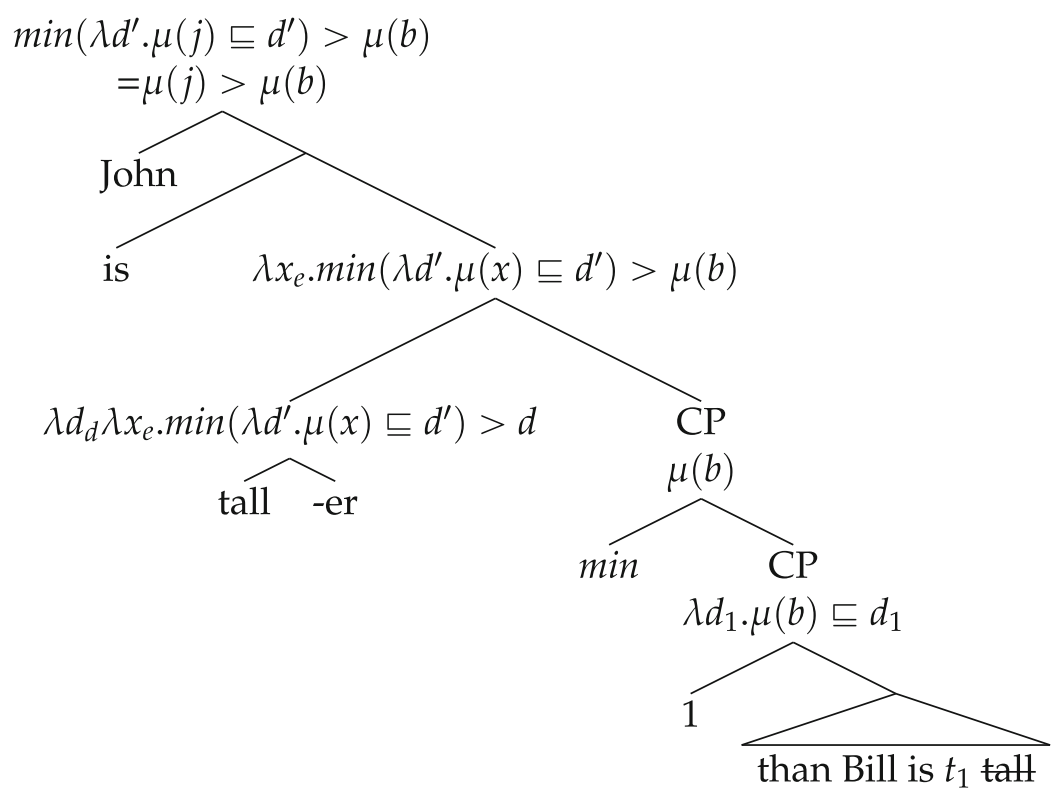

Fig. 1 Syntax and interpretation of (25)

2014). Alternatively, the comparative morpheme might form a constituent with the than-clause and only later combine with the adjective (Bresnan 1973; Carlson 1977; von Stechow 1984; Heim 2000; Bhatt and Pancheva 2004). The choice is largely orthogonal to our study, but the former option makes the combination of degree and plural semantics slightly easier, hence our choice, which leads us to the following interpretation of the comparative:

$$
\llbracket \text {-er } \rrbracket=\lambda g_{\langle d,\langle e, t\rangle\rangle} \lambda d_{d} \lambda x_{e} \cdot \min \left(\lambda d^{\prime} \cdot g\left(d^{\prime}, x\right)\right)>d
$$

Turning our attention now to the interpretation of the than-clause, we note that its semantic composition includes operator movement (Chomsky 1977), resulting in lambda abstraction over degrees, and, as in Beck's analysis, the min operator. Unlike Beck, we dispense with the second selection step (her max operator). Notice that the than-clause of Fig. 1 is going to collect all pluralities that contain Bill's height. So this is a set that has among its members spurious plural individuals like Mary's height $\sqcup$ Bill's height, or the individual that contains everyone's height. Applying the minimality operator min yields a single individual, namely Bill's height. Similarly, the matrix adjective would be true of spurious plural individuals that include, among their members, John's height. Here again, applying min yields a single individual, namely John's height. Thus, min selects the most informative plurality both in the matrix clause and in the than-clause, and can be compared to the work of min and max operators selecting the most informative element in a set, as commonly posited in analyses of comparatives (von Stechow 1984; Heim 2006; Beck 2010). 
In the example above, there is no reason to apply plurality semantics to degrees since the matrix clause and the than-clause denote atomic individuals. Things change once we turn to quantified examples:

$$
\text { John is taller than every girl is. }
$$

In (28), we give the interpretation of than every girl.

$$
\lambda d . \forall x[\operatorname{girl}(x) \rightarrow \mu(x) \sqsubseteq d]
$$

This is the set of pluralities that contain at least the heights of all the girls. So, if there are three girls who are respectively 150, 160, and 190 centimetres tall, then this set contains $150 \sqcup 160 \sqcup 190$ and all sums that contain this particular sum as a proper part. Minimality reduces this set to the individual $150 \sqcup 160 \sqcup 190$ itself:

$$
\begin{aligned}
\llbracket \min (\text { than every } \operatorname{girl}) \rrbracket & =\min (\lambda d . \forall x[\operatorname{girl}(x) \rightarrow \mu(x) \sqsubseteq d]) \\
& =150 \sqcup 160 \sqcup 190
\end{aligned}
$$

If we proceeded with composition in the same way as in Figure 1, the sentence would end up meaning (30).

$$
\text { John's height }>150 \sqcup 160 \sqcup 190
$$

(undefined)

The expression in (30) is undefined because $>$ only relates atomic entities. Previous accounts avoid analogous meaningless comparisons in various ways. As discussed above, Beck (2010) uses a special selection mechanism, which selects just one degree, so that the comparison can go through. We could follow suit and use some sort of maximality operator to select the highest atom in the plurality denoted by the than-clause, in which case the truth conditions for (27) will correctly become John's height $>190$.

But there is no need for such special mechanisms. Examples completely parallel to (30) are the bread and butter of semanticists working on pluralities, and several operations have been developed to deal with cases in which a plurality combines with a predicate restricted to atoms. One of them is to pluralise the predicate roughly corresponding to John is taller. Such pluralisation results in:

$$
* \lambda d \cdot \min \left(\lambda d_{2} . \text { John's height } \sqsubseteq d_{2}\right)>d
$$

This expression can straightforwardly combine with $150 \sqcup 160 \sqcup 190$. Given the nature of $*$ and the atomic requirement of $>$, the resulting interpretation is true iff each of the atoms of $150 \sqcup 160 \sqcup 190$ is smaller than John's height; that is, John is taller than any of the girls. The semantic composition of this derivation, shown in Fig. 2, assumes nothing beyond standard mechanisms of the semantics of pluralities. The only difference from Fig. 1 is that now, we also have to postulate movement of the than-clause, so that a predicate is created to which the $*$-operator can be applied. This step is not postulated ad hoc: in the semantics of pluralities, this kind of movement is generally required for distributive readings of any arguments other than subjects (but see Lasersohn 1998 for an account of distributivity that dispenses with this movement, which we do not follow here to keep our semantics relatively simple). 


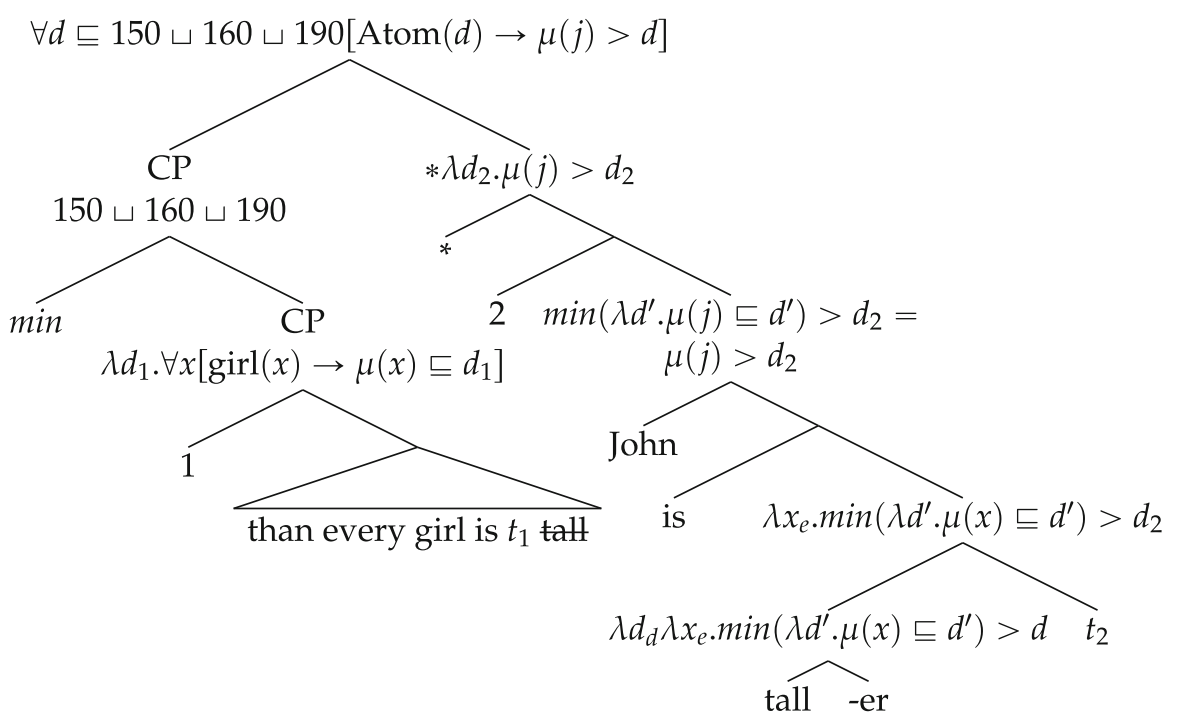

Fig. 2 Syntax and interpretation of (27)

An alternative option is to pluralise relations, not predicates. In our scenario, this boils down to pluralising the comparative after it has applied to the adjective. (This means we would analyse the sentence as John is **(tall er) than every girl.) This yields the following statement:

$$
\langle 150 \sqcup 160 \sqcup 190, \text { John }\rangle \in * * \lambda d_{d} \lambda x_{e} \cdot \min \left(\lambda d^{\prime} \cdot \mu(x) \sqsubseteq d^{\prime}\right)>d
$$

Since John is an atomic individual, (32) is equivalent to (33), which in turn is the interpretation of the root node of Fig. 2.

$$
150 \sqcup 160 \sqcup 190 \in *^{*} \lambda d_{d} \cdot \min \left(\lambda d^{\prime} . \mu(j) \sqsubseteq d^{\prime}\right)>d
$$

Note that (32) and (33) are equivalent to (34), which captures a truly cumulative interpretation of the comparative relation.

$$
\text { John's height } * *>150 \sqcup 160 \sqcup 190
$$

In summary, our plural degrees framework provides two natural and equivalent interpretations for (27): one where the than-clause plurality is the subject of a distributive predicate and one where it enters into a cumulative comparison relation with the subject. In both derivations, John has to be taller than the tallest girl. This is also the result of the accounts discussed in Sect. 2. However, we obtained the correct interpretation without postulating an island-violating QR. Moreover, unlike Beck, we did not need to invoke a combination of a minimality operator $(\mathrm{min})$ and a maximality operator ( $\max$, picking the top degree in an interval). Instead we used minimality in tandem with an independently motivated pluralisation operator. In this sense, our approach is simpler, since it does away with the two-tier selection procedure of Beck's in favour of a single informativity-optimising operation. By leaning on Beck's selection innova- 
tion, we also avoid the problem of the negation approaches discussed in Sect. 2-that is, how to exclude an empirically absent interpretation - since we derive a single, unambiguous reading.

We hasten to add that we are not the first to suggest this modification of Beck (2010). In fact, it was Beck herself, in Beck (2014), who realized that using degree pluralities would yield a simpler, single-layer analysis of than-clauses. There is considerable overlap between the framework presented there and the ideas that have been (independently) developed by us in this paper. Specifically, just as we did here, Beck also proposes that the illusion of a wide-scope interpretation of the quantifier in a than-clause is due to a cumulative interpretation. One key difference, however, is how the pluralities are introduced into the semantics. Beck's analysis crucially relies on the assumption that we can assign group interpretations to quantifiers like every NP: for instance, every girl ends up referring to the plurality of all girls. While there is some evidence for such interpretations with every (Schein 1993; Kratzer 2003; Champollion 2010a), it seems to be the case that the universal quantifier can be interpreted non-distributively only when it is not the highest argument (e.g., when it is an object). This option would not be available for the example discussed above. Furthermore, each NP is even less likely to be interpreted as a group. Beck acknowledges that her assumption leads to potentially problematic predictions. (See Beck 2014, pp. 101-102 for discussion. $)^{3}$

In contrast to Beck (2014), in our approach the pluralities involved in the distributive and cumulative interpretations above are only indirectly formed by the than-clause quantifier. We posit that adjectives express relations between entities and degree pluralities. In than-clauses, quantifiers scoping over the adjective cause the minimal degree denoted by the than-clause to be non-atomic. A crucial difference, then, between our approach and that of Beck (2014) is that we assume adjectives to be inherently plural.

One could wonder, as did one of our reviewers, whether we could do without this assumption. As pointed out by this referee, there is a potentially interesting parallel to the discussion in Heim (2006). Heim holds on to the simple degree relation interpretation of adjectives in (35) and proposes an optional operator, the so-called point-to-interval operator $\Pi$, that lifts a property of degrees to a property of intervals. (Heim attributes the idea for this operator to Roger Schwarzschild, who in turn built on earlier unpublished work by Heim.)

$$
\begin{aligned}
& \llbracket \text { tall } \rrbracket=\lambda d_{d} \cdot \lambda x_{e} \cdot \operatorname{height}(x) \geq d \\
& \llbracket \Pi \rrbracket=\lambda D_{\langle d, t\rangle} \cdot \lambda D_{\langle d, t\rangle}^{\prime} \cdot \max \left(D^{\prime}\right) \in D
\end{aligned}
$$

We could follow suit and take (35) to be the interpretation of adjectives, while introducing an operator that parallels $\Pi$, such as $\Pi$ (point-to-plurality) in (37).

\footnotetext{
${ }^{3}$ Our analysis is also reminiscent of Beck (2012), who like us introduces a mechanism of distributive quantification over atoms in a degree plurality. However, Beck only uses this mechanism for cases involving existential quantifiers (in particular, existential modals), where her selection mechanism yields a set of minimal intervals, rather than a single atomic minimal interval. In effect, apart from a superficial similarity between the mechanisms used, there is no overlap whatsoever in the analyses we offer for particular cases. In particular, Beck (2012) does not aim to provide an extensive argument in favour of a plural semantics, which we do aspire to here.
} 


$$
\llbracket \Pi \rrbracket=\lambda d_{d} \cdot \lambda D_{\langle d, t\rangle} \cdot \max (D) \sqsubseteq d
$$

Using the interpretation for adjectives in (35) and $\Pi$ in (37), we can obtain the same result as before. In particular, as before, we can derive the term $\lambda d . \forall x[\operatorname{girl}(x) \rightarrow$ $\mu(x) \sqsubseteq d]$ as the interpretation of the CP node that is fed to the minimality operator in the than-clause, as illustrated in (38).

$$
\begin{aligned}
& \lambda d . \forall x[\operatorname{girl}(x) \rightarrow \mu(x) \sqsubseteq d] \\
& \mathrm{WH}_{2} \quad \forall x\left[\operatorname{girl}(x) \rightarrow \mu(x) \sqsubseteq d_{2}\right] \\
& \text { every } \lambda x \cdot \mu(x) \sqsubseteq d_{2} \\
& \text { girl } \\
& 3 \mu(x) \sqsubseteq d_{2} \\
& \lambda D \text {.max }(D) \sqsubseteq d_{2} \quad \lambda d . \mu(x) \geq d \\
& \lambda d . \lambda \operatorname{D.max}(D) \sqsubseteq d \quad d_{2} \\
& \text { ПП } t_{2} \\
& \overbrace{\overbrace{x} \overbrace{d_{3}}^{\lambda x \cdot \mu(x)}}^{\mu(x) \geq d_{1}} \overbrace{d_{1}}^{\lambda d \lambda x \cdot \mu(x)} \geq d
\end{aligned}
$$

This is not the only derivation that is possible, however. We could choose to scope $\Pi$ over the quantifier, in which case we get (39), which returns the set of degree pluralities that contain the height of the shortest girl. As should be more than clear from the discussion above, such a derivation is undesirable. For a semantics based on (35) to work, we would therefore need to somehow limit the scope options of $\Pi$.

$$
\begin{aligned}
& \lambda d_{2} \cdot\left(\Pi\left(d_{2}\right)\right)(\lambda d \cdot \forall x[\operatorname{girl}(x) \rightarrow \mu(x) \geq d]) \\
& =\lambda d_{2} \cdot \max (\lambda d \cdot \forall x[\operatorname{girl}(x) \rightarrow \mu(x) \geq d]) \sqsubseteq d_{2}
\end{aligned}
$$

This makes the parallel to Heim (2006) complete, since Heim too needs to assume that $\Pi$ comes with a set of very specific scope constraints. This seems a good enough reason for us to stick with our approach of making adjectives inherently plural, thereby avoiding the introduction of an additional covert operator in tandem with an additional set of constraints. That said, as pointed out by Heim, there are also advantages to the complications brought by $\Pi$ when dealing with certain modal quantifiers. We will therefore briefly return to analyses along the line of (38) when we turn to modals in the final section of this paper.

Before doing so, we will assess the more immediate consequences of degree pluralities. First of all, if the comparative may express cumulative relations between entities and plural degrees, then we expect to see more outlandish readings involving plural subjects. In particular, we expect to see cases where the cumulative and distributive reading are truth-conditionally distinct. We will present a careful argument in Sect. 6 
that there exist examples that require a cumulative interpretation and that these examples are highly problematic for frameworks that lack reference to degree pluralities. In the next section, we will start, however, with a second advantage: our framework straightforwardly extends to differentials.

\section{Differentials}

Beck discusses a problem with her theory with respect to sentences like (40) (Beck 2010, Sect. 3.4). The intuitive interpretation is as in (41).

(40) John is exactly 2 inches taller than every girl is.

(41) For every girl $x$ : John is exactly 2 inches taller than $x$.

That is, (40) entails that the girls all have the same height. This does not follow from Beck's analysis, however. The reason is that on her account, the than-clause selects the maximum degree out of the individual girls' heights. John's height is then compared to that degree, irrespective of the height of the other girls. If the girls' heights are 150 , 160, and $190 \mathrm{~cm}$, we get:

$$
\text { John is exactly } 2 \text { inches taller than } \max ([150 \ldots 190])
$$

The result is that there is no hope for this analysis to predict an entailment that the girls in question have the same height. Our theory certainly holds more potential in this regard. Pseudo-formally, the semantics we predict will be along the lines of (43).

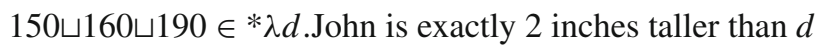

If the girls have different heights, as in this scenario, (43) can clearly never be true, and so we predict that differentials such as (40) entail that the girls have equal height. In other words, we predict that such sentences can only be true if the than-clause denotes an atomic degree.

Let us see in somewhat more detail how we derive this result. We follow Schwarzschild (2008) in assuming (i) that measure phrases express predicates over intervals (type $\langle\langle d, t\rangle, t\rangle$ ), and (ii) that the differential construction applies the measure phrase to the gap between the matrix and the than-clause degree. If $d$ and $d^{\prime}$ are two degrees, then we write $d \rightarrow d^{\prime}$ for the interval that spans from $d$ upwards to $d^{\prime}$ : $d \rightarrow d^{\prime}:=\left\{d^{\prime \prime} \mid d \leq d^{\prime \prime}<d^{\prime}\right\}$. (Note that the interval is empty if $d>d^{\prime}$.)

Based on this mechanism, we propose the semantics of differential comparison in (45). Compare this to the original entry for comparative morphology repeated in (44). ${ }^{4}$

\footnotetext{
4 Crucially, (44) and (45) are related in the following way: $\llbracket-e r \rrbracket(g)(d)(x) \Leftrightarrow \exists m[\emptyset \notin m \wedge$ $\llbracket-e r_{\text {diff }} \rrbracket(g)(d)(m)(x)$ (under a few natural assumptions for $m$, the measure phrase). This is because if $\min \left(\lambda d^{\prime} \cdot g\left(d^{\prime}, x\right)\right)>d$ then $d \rightarrow \min \left(\lambda d^{\prime} \cdot g\left(d^{\prime}, x\right)\right)$ is non-empty. Assuming that $m$, the measure phrase, can be of any size, it follows that $m\left(d \rightarrow \min \left(\lambda d^{\prime} \cdot g\left(d^{\prime}, x\right)\right)\right)$ is true for some (non-empty) $m$. Similarly, if $m\left(d \rightarrow \min \left(\lambda d^{\prime} \cdot g\left(d^{\prime}, x\right)\right)\right.$ is true for some non-empty $m$, which can be of any size but greater than zero, it follows that $d \rightarrow \min \left(\lambda d^{\prime} \cdot g\left(d^{\prime}, x\right)\right)$ is not empty. Since $m$ is non-zero, it follows that $d \rightarrow \min \left(\lambda d^{\prime} \cdot g\left(d^{\prime}, x\right)\right)$ has at least two endpoints, and consequently $\min \left(\lambda d^{\prime} \cdot g\left(d^{\prime}, x\right)\right)>d$.
} 


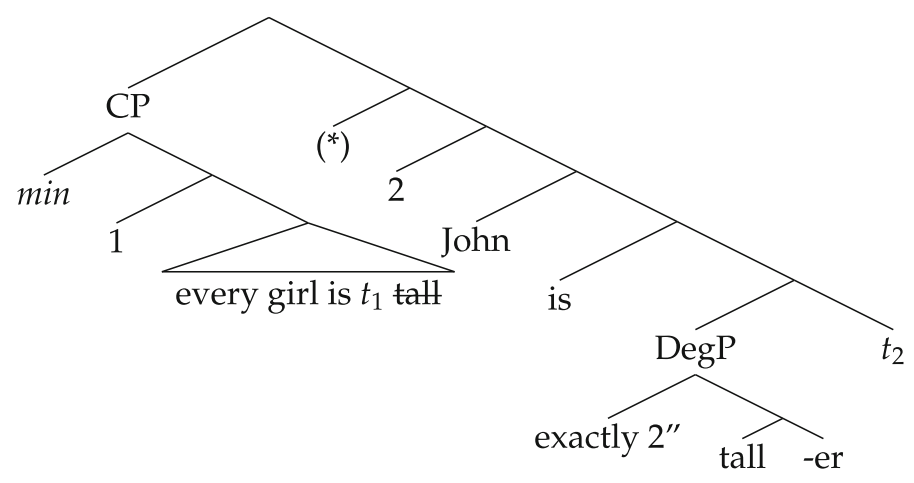

Fig. 3 Structure of (40)

$$
\begin{aligned}
& \llbracket-\mathrm{er} \rrbracket=\lambda g_{\langle d,\langle e, t\rangle\rangle} \cdot \lambda d_{d} \cdot \lambda x_{e} \cdot \min \left(\lambda d^{\prime} \cdot g\left(d^{\prime}, x\right)\right)>d \\
& \llbracket-\mathrm{er}_{\mathrm{diff}} \rrbracket=\lambda g_{\langle d,\langle e, t\rangle\rangle} \cdot \lambda m_{\langle d t, t\rangle} \cdot \lambda d_{d} \cdot \lambda x_{e} \cdot m\left(d \rightarrow \min \left(\lambda d^{\prime} \cdot g\left(d^{\prime}, x\right)\right)\right)
\end{aligned}
$$

The basic structure we assume is that in Fig. 3. Here, the CP corresponding to the thanclause has moved out. This is not strictly necessary, but it does become necessary if we assume that the comparative is read distributively.

Let $2 I N$ express a predicate over degree intervals such that it returns true if and only if the endpoints of the interval are 2 inches apart. This will be how we interpret the measure phrase. Correspondingly, the DegP is interpreted as follows:

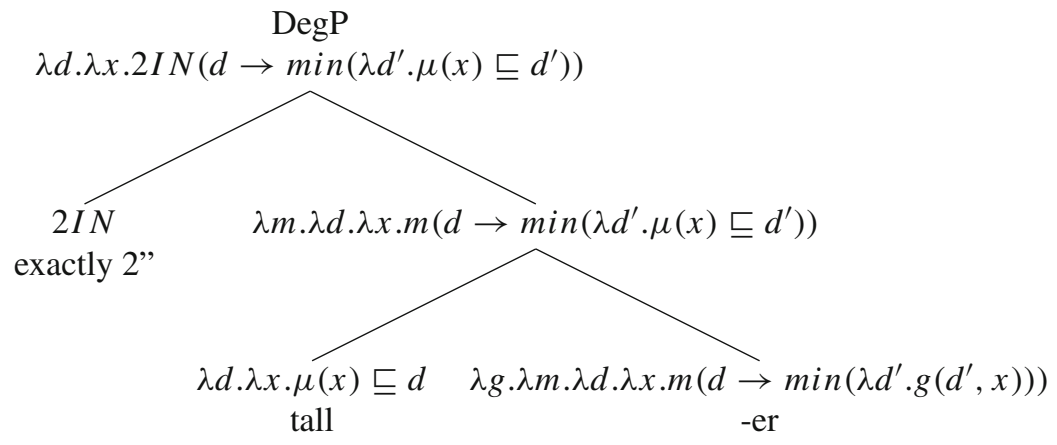

Note that $\operatorname{DegP}$ only makes sense if $x$ is an atom: $\min \left(\lambda d^{\prime} \cdot g\left(d^{\prime}, x\right)\right)$ may return a non-atomic degree plurality if $x$ is a plural entity but the interval constructor $\rightarrow$ is not defined on plural degrees. Effectively, this means that if the subject of the differential is plural, one would need to cumulate the predicate it combines with. In this sense, differentials are inherently distributive predicates, just like comparatives are. (Alternatively, we could say they are inherently cumulative.)

The next step in the derivation is to combine the DegP with the trace of the thanclause and then fill in the subject slot. Let $d_{t h}$ be the degree plurality denoted by the than-clause. Then the end result is: 


$$
\begin{aligned}
& d_{t h} \in * \lambda d .2 I N\left(d \rightarrow \min \left(\lambda d^{\prime} . \mu(j) \sqsubseteq d^{\prime}\right)\right) \\
& \equiv d_{t h} \in * \lambda d .2 I N(d \rightarrow \mu(j))
\end{aligned}
$$

This is only true if all the atoms in $d_{t h}$ are exactly 2 inches below John's height. In other words, this is only true if $d_{t h}$ is itself an atom. That, in turn, is only possible if the girls in question all have the same height, namely John's height minus 2 inches. 5

We have now shown that our proposal can successfully analyse non-monotonic differentials. This is not the only type of differential where our account provides a natural solution to the data. To show this, let us first characterise the data a bit more clearly.

As we claimed above, just as normal comparatives give the impression of wide scope quantification by the quantifier in the than-clause, so do differentials. This is irrespective of the kind of measure phrase we find in the differential slot, as can be seen by the wide-scope paraphrases in (51)-(53) of the respectively upward, nonmonotonic, and downward monotone differentials in (48)-(50).

(48) John is more than 2 inches taller than every girl.

(49) John is exactly 2 inches taller than every girl.

(50) John is less than 2 inches taller than every girl.

(51) Every girl is such that John is more than 2 inches taller than her.

(52) Every girl is such that John is exactly 2 inches taller than her.

(53) Every girl is such that John is less than 2 inches taller than her.

In our approach so far, we have accounted for (49) not by quantifying over girls, but rather by distributing over the plural degree slot corresponding to the than-clause. Importantly, this analysis extends to the other cases. That is, (48) is interpreted in our account as (54), while (50) is interpreted as (55). Here, $>2 I N$ and $<2 I N$ express the set of intervals of which the endpoints are more than 2 inches and less than 2 inches apart, respectively.

$$
\begin{aligned}
& \llbracket \text { than-clause } \rrbracket * \lambda d .>2 I N(d \rightarrow \mu(j)) \\
& \llbracket \text { than-clause } \rrbracket \in * \lambda d .<2 I N(d \rightarrow \mu(j))
\end{aligned}
$$

While other existing accounts have no problems with (48), the downward-monotone differential in (50) is problematic for several of them. We refer to Fleisher (to appear)

\footnotetext{
5 As in the previous section, since there is but one plural argument in the -er relation, the distributive and cumulative reading collapse. This means we could, in principle, arrive at the same result assuming cumulation of -er. However, since differentials require a three-place comparison relation, we would need to assume an operator that cumulates three-place predicates: *** $R$ is the smallest superset of $R$ such that if $\langle a, b, c\rangle \in *_{*}^{*} R$ and $\left\langle a^{\prime}, b^{\prime}, c^{\prime}\right\rangle \in * * * R$, then also $\left\langle a \sqcup a^{\prime}, b \sqcup b^{\prime}, c \sqcup c^{\prime}\right\rangle \in * * * R$. (An independent example where we may need such an operator would be: John, Bill, and Mary are exactly 2, exactly 4, and exactly 6 inches taller than their mothers.)
} 
for an extensive exposé of the issues all of the contestants in the current theoretical landscape are running into. Here we will briefly lay out how differentials constitute an area where our relatively conservative variation on Beck's theory yields an altogether different set of predictions. As we showed, the quirky interpretation of differentials follows neatly from our approach. The reason for this is that, contrary to Beck's analysis, we have not assumed that than-clauses contain a maximality operator. The problem created by such an operator is that in sentences like (48)-(50), John's height is going to be (differentially) compared to a single degree. As seen by the paraphrases in (51)-(53), the data show something different, though. John needs to be in the differential relation expressed by the measure phrase to all entities in the domain of quantification, not just to its maximal, minimal, or any other specific individual. That Beck's approach fares well in (48) is a happy coincidence, due to the fact that if John's height exceeds the height of the tallest girl by at least some measure, his height will also exceed the height of any of the other girls by at least that measure. In contrast, our account can accommodate all of the examples in (48)-(50) because the than-clauses retain the information about every girl's height. ${ }^{6}$

\section{Cumulative comparison}

The plural machinery we adopt creates the prediction that we should find a variety of plural-related readings. In particular, we predict that genuine cumulative readings exist - that is, cumulative readings that are not equivalent to distributive construals in the way we saw above. In this section, we show that this prediction is correct.

We start by noting that some mention of such readings already appears in previous literature (Scha and Stallard 1988; Schwarzschild 1996; Matushansky and Ruys 2006). For instance, Scha and Stallard give the following example, which does not require that every frigate was faster than any carrier; it suffices that every frigate was faster

\footnotetext{
6 Beck (2010) discusses examples in which differentials seem to measure the gap only from the maximal point of the set of degrees. For example, 4 seconds in (i) measures the gap between the winner of the race and the second-fastest cyclist.
}

(i) WOW! Almost 4 seconds faster than everyone else, and a 9-second gap on Lance.

This example would follow under our account if the numeral in the differential was understood as uppermonotonic. (Beck mentions that she did not find any clear examples of the same type with an exactlydifferential.) However, our analysis of than-clauses opens up another possibility for analysing cases such as (i). We have argued that degree pluralities can participate in distributive and cumulative readings. But if the parallel to pluralities is complete, there might also be collective readings for degree pluralities-i.e., readings in which the plurality of degrees is understood as a collection. Given the requirement of atomicity on $>$, the collection would have to be an atomic degree that is somehow a representative of the whole plurality. It seems conceivable to us that the highest degree in races would be a natural representative, and this would capture the right interpretation of (i). In other examples, a different degree might be considered to be the right representative; in (ii), for instance (from Beck 2010, p. 55), it might be an average.

(ii) Ben was almost a year older than everyone else in his class.

We leave further investigation of this possibility to future research. 
than some carrier, and every carrier slower than some frigate. In other words, this is a cumulative reading. (See Schwarzschild 1996, p. 89, for further discussion of this reading.)

The frigates were faster than the carriers.

One could potentially analyse (56) as a cumulative relation between two plural entities, viz. the frigates and the carriers. This is indeed what Scha and Stallard (1988), Schwarzschild (1996), and Matushansky and Ruys (2006) do. However, we can now offer an analysis in terms of a cumulative relation between degrees. The idea is that the sentence will yield a degree plurality made up of all and only the speeds of the individual frigates, call this plurality $f$, while the than-phrase denotes the sum of all the carrier speeds, $c$. Sentence (56) is now true if and only if $f * *>c$. What this means is that for each atomic speed in $f$, there is an atomic slower speed in $c$, and for each atomic speed in $c$ there is an atomic speed in $f$ that is faster. This is equivalent to saying that the frigates and carriers stand in the cumulative relation $* * \lambda x . \lambda y . x$ 's speed $>y$ 's speed.

The fact that there is an equivalence between an analysis of (56) in terms of a cumulative relation between degrees and one in terms of a cumulative relation between entities means that we cannot use such examples as an argument that our approach is on the right track. Clearly, one does not need to assume the existence of degree pluralities to account for examples like (56). However, as we will show now, there exist examples that, if we are right, can only be analysed using the kind of framework we are proposing.

We start by considering a minimal variation on (56), namely its clausal comparative counterpart.

The frigates were faster than the carriers were.

For such a clausal comparative, an interpretation using a cumulative relation between entities is problematic. The reason is that the only way to get at such an interpretation is by quantifier raising the subject of the than-clause, as in (58). For a number of reasons, which we will explain in more detail below, such a derivation goes against normal assumptions on movement.

[ The frigates [ the carriers [**[1[ were faster than $t_{1}$ were fast ] ] ] ]

A way out would be to deny that (57) is cumulative in the first place. We could follow the reasoning in Winter (2000) for other purported cumulative readings and claim that (57) is a distributive reading where the definite description the carriers functionally depends on quantification over the frigates. Informally:

(59) The frigates $\mathrm{EACH}_{i}$ were faster than the carriers $i$ were.

The idea would be that (59) allows a reading where each frigate is only faster than its carriers. The possessive relation could then be specified in pragmatics (the sentence could, for example, mean that each frigate is faster than the carriers in the area of the frigate, which is the cumulative reading discussed in Schwarzschild 1996). Thus, this 
would create the illusion of a cumulative relation. As Winter extensively argues for the examples in his paper, such an analysis is not unlikely, given the fact that examples like (60) exist. Here, the most salient reading is one in which each student hands in only the essays that (say) he or she wrote.

(60) Each student managed to hand the essays in on time.

So, although (57) has a cumulative-like reading and although it is impossible to derive that reading as a cumulative relation between frigates and carriers, this is still not enough to argue for the need of a cumulative comparison relation between degree pluralities, for it could simply be that the proper interpretation for such sentences is a Winter-style dependency analysis. To support our approach, we should therefore be on the lookout for examples that have cumulative-like readings, but for which a dependency analysis is unavailable. We believe $(61)^{7}$ is such an example.

(61) The state economies of Ireland, the Netherlands, and Australia all scored higher than they each did in the mid-1980s.

In the relevant reading, the state economy of Ireland scored higher now than it did in the 1980s, the state economy of the Netherlands showed similar improvement as compared to the mid-1980s, and so did Australia's economy. Crucially, on this reading the three economies are not compared to each other, so it could be that Ireland's state economy now does not score higher than Australia's economy in the mid-1980s, etc.

What makes this sentence interesting is that a dependency analysis, as in (62), is out of the question.

(62) The state economies of Ireland, the Netherlands, and Australia $\mathrm{EACH}_{i}$ scored higher than they $i$ each did in the mid-1980s.

The problem with (62) is the occurrence of each in the than-clause. In the relevant reading, they will refer to a singular economy (bound by distributive quantification over the matrix subject), and so each is vacuous and infelicitous. One can see this effect by looking at examples that resemble the analysis in (62).

a. The boys all think they won the race.

b. \#The boys all think they each won the race.

c. The boys all think that they each failed the course.

The example in (65a) has a dependent reading: each boy thinks that he won the race. This reading disappears once we add the distributive quantifier each. In fact, the only reading available for $(65 \mathrm{~b})$ is one in which the boys each have the contradictory thought that each of them is the winner of the race. A similar observation can be made for (65c). The reading that is available is one in which the boys all have the same thought: all the boys failed. What is missing is a dependent reading, in which each boy only thinks of himself that he has failed the course.

\footnotetext{
7 Simplified from www. oapen. org / download? type=document\&docid=340206.
} 
Given these observations, we can conclude that the cumulative-like reading of (61) cannot be due to a dependent interpretation of the plural pronoun, but that this sentence is genuinely cumulative. Given that, once more, at no point in the composition there is a cumulative relation between entities, we conclude that (61) is an instance of a cumulative relation that involves a degree plurality, namely the one corresponding to the denotation of the than-clause. ${ }^{8}$

Let us now see what our analysis of example (61) consists of in detail. Its than-clause (prior to applying minimality) is interpreted as follows.

$$
\begin{aligned}
& \lambda d \text {. the state economies of Ireland, the Netherlands, and Australia each scored } \\
& d \text {-high in the mid-1980s. }
\end{aligned}
$$

This is the set of degree pluralities that at least contain the three economies' scores in the mid-1980s. For ease of exposition, let's write IE, NL, and AU for the three state economies in question and IE80, NL80, and AU80 for the respective scores in the mid1980s (as well as, accordingly, IE15, NL15, AU15 for the current scores). That is, (64)

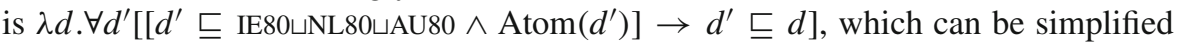

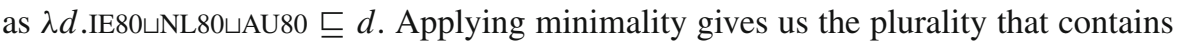

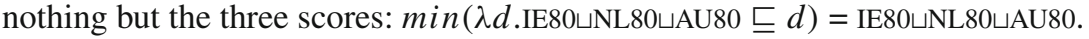

The structure of the rest of the derivation is now:

\footnotetext{
${ }^{8}$ Examples like (61) are not very common, but more of the same kind can be found, e.g., the two sentences in (i).

(i) a. the Petes (...) scored at least one try more than every opponent (in the games of the season) (from http://www.thesundayleader.lk/2010/09/12/the-unbeaten-peterite-rugby-teamof-2010/)

b. The Baltimore Ravens scored more points than each of their opponents (at three playoff games). (from http://thirddownconversion.com/2013/01/23/one-reason-why-baltimore-is-in-the-superbowl/, simplified)
}

In both cases, the cumulative interpretation is probably the intended interpretation. In the context of (i-a), it is mentioned that the Petes scored four or more tries and that they beat each opponent at least by one try, including the opponents that scored four tries. For (i-b) it is relevant that the actual scores were 24-9, 38-35, and 28-13 (the first element in each pair is what the Baltimore Ravens scored, the second element what the opponent scored). Thus, the distributive reading would be false since one of the opponents scored 35 points, and the Baltimore Ravens scored less than that on two occasions. It appears, then, that there is a cumulative relation between the points the opponents scored and individual games in (i-a), and similarly, there is a cumulative relation between the number of tries and individual games in (i-a). We note that the examples might be analysed as phrasal comparatives, but the crucial readings remain if we change the sentences into clausal comparatives, by adding scored or did to the than-clauses. 
(65)

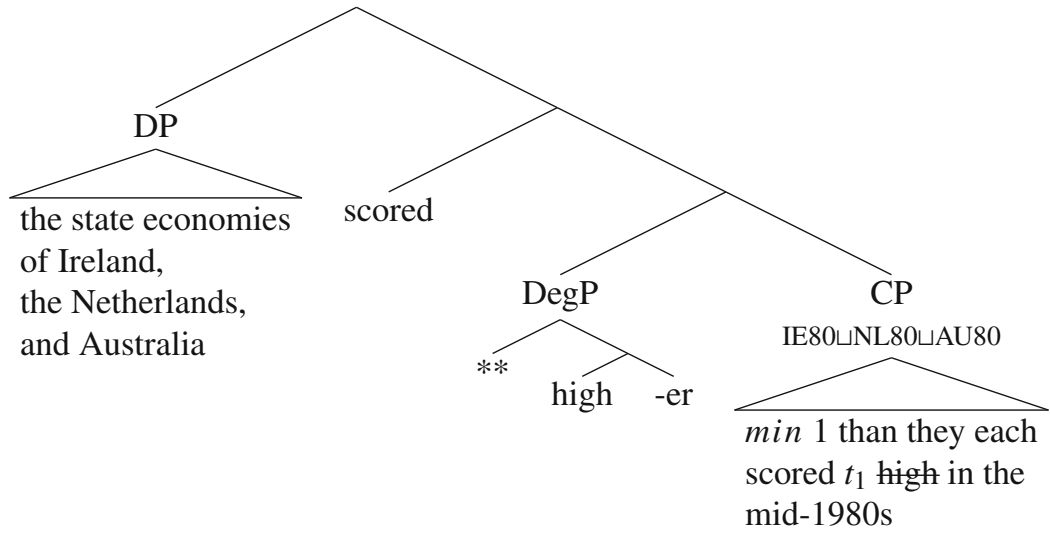

The cumulative relation in DegP expresses:

$$
* * \lambda d_{d} \lambda x_{e} \cdot \min \left(\lambda d^{\prime} \cdot \mu(x) \sqsubseteq d^{\prime}\right)>d
$$

and so we get the following truth conditions for (61): ${ }^{9}$

$$
\langle\mathrm{IE} 80 \sqcup \mathrm{NL} 80 \sqcup \mathrm{AU} 80, \mathrm{IE} \sqcup \mathrm{NL} \sqcup \mathrm{AU}\rangle \in * * \lambda d_{d} \lambda x_{e} \cdot \min \left(\lambda d^{\prime} . \mu(x) \sqsubseteq d^{\prime}\right)>d
$$

which in turn is equivalent to:

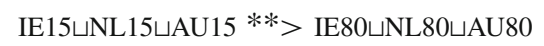

The most salient state of affairs that makes (68) true is in case IE15 > IE80, NL15 $>$ NL80, and AU15 > AU80, which coincides with the intended reading for (61). One could object at this point that the truth conditions in (68) are very weak, weaker than intuitions would let us believe are appropriate for such sentences, since there are many alternative situations that make (68) true as well. As we will show below, this is a general issue with cumulative readings; but we will argue that with the right kind of pragmatic strengthening in place, our predictions are still on target. Before we turn

\footnotetext{
9 We have ignored the contribution of the verb to score in the analysis. This is not directly relevant for our point, but to complete the derivation, we will indicate how its contribution could be analysed. One option is to assume that to score is a relation between entities and the points they scored, i.e.: $\lambda y \lambda x$. $\operatorname{score}(x, y)$. In (65), the object of score is:
}

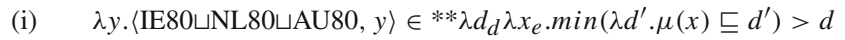

The verb and (i) can combine via predicate modification, either directly or, if we allow predicate modification to work only on type $\langle e, t\rangle$ (cf. Heim and Kratzer 1998), after score combines with its subject and the object remains as the only argument. (This could be achieved, for example, by movement of DegP+CP out of its original position.) In either case, the resulting interpretation would be:

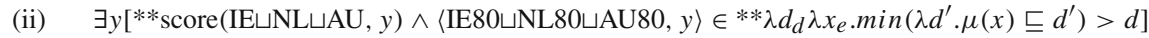

Note two things in (ii). First, we have to apply ** to the relation score as well. Second, $x$ in (ii) now expresses scores, and the function $\mu$ can consequently be seen as just the identity function or as a rather trivial mapping of scores to degrees. In the simplified (67), the function $\mu$ would have to relate states to their scores. 
to this, however, let us first explore how other theories of the comparative would fare with examples like (61) that require cumulative relations involving degrees.

Cumulating degrees is not possible in the other accounts of comparatives - the interval strategy and the negation strategy. Take, for example, Beck's selection approach. In that analysis, the than-clause of (61) yields only a single degree, the highest of \{IE80, NL80, AU80\}. The only available reading is that IE15, NL15, and AU15 are all higher than the highest score of the mid-1980s economies. In the negation strategy, the than-clause is interpreted as the interval that extends upward from the highest score in $\{$ IE80, NL80, AU80\} (see Sect. 2). Here again, the end result of the than-clause destroys the information regarding the individual degrees, IE80, NL80, AU80, and the ** operator cannot be successfully applied.

There is one possibility open to the previous accounts of comparatives, namely to cumulate directly on plural entities, following Scha and Stallard (1988), Schwarzschild (1996), and Matushansky and Ruys (2006). We have already noted that this strategy should not be used in (61). Let us discuss its problems in more detail now. To capture the reading, one could let they each move to the matrix clause, so that the following cumulative relation between entities is obtained:

$$
* * \lambda x_{e} \cdot \lambda y_{e} \cdot \min \left(\lambda d^{\prime} . x \text { 's score } \sqsubseteq d^{\prime}\right)>\min (\lambda d . y \text { 's 1980-score } \sqsubseteq d)
$$

This cumulative relation can then combine with the pair $\langle$ IE $\sqcup \mathrm{NL} \sqcup \mathrm{AU}$, they each $\rangle$. If they each was interpreted in the same way as the first argument, the formula would yield the correct truth conditions.

There are two problems with this analysis. First, they each would have to move out of an island, the than-clause. Allowing this would nullify all of the research on comparatives since von Stechow (1984), which got rid of such syntactically illicit transformations in the interpretation of than-clauses. (See also Beck and Sauerland 2000 for evidence that DPs cannot move out of an island to enter cumulative readings.)

Second, it is not clear how the analysis can deal with the floating each in the thanclause. Above, we assumed that each moves together with they. But then, how should it be interpreted? Floating each is commonly treated as a predicate modifier, specifying that the predicate is interpreted distributively (Dowty and Brodie 1984; Link 1987; Roberts 1987; Schwarzschild 1996; Champollion 2010b). Here, however, each would have to combine with a cumulative relation, which is normally prohibited. Notice, for example, that (70) lacks the cumulative reading that John lifted one sofa and Mary lifted another sofa.

\section{John and Mary each lifted two sofas.}

Alternatively, each could be stranded in the than-clause. This is problematic, too: the than-clause in (69) has an atomic subject, $y$. Since distributive and non-distributive predicates behave alike with atomic subjects, each modifying the predicate in the than-clause would become vacuous. But vacuous quantification of each is normally prohibited (see, e.g., Roberts 1987; Hoeksema 1996):

*Every boy/John each left. 
To sum up, cumulation on degrees seems unavoidable. Examples like (61) strongly support our point that than-clauses should yield not just a single degree, or a degree interval, but a degree plurality. It is a virtue of an account working with degree pluralities that it correctly derives the most salient reading of (61).

As we hinted at above, our analysis derives more than the salient reading. All we require is that $(72)$ be true. Given the definition of $* *$, this is the case if each state scored higher now than it did in the mid-1980s. But there are other possibilities. For instance, the sentence would be true in this situation: IE15 > AU80, AU15 > NL80, and NL15 > IE80. But this is definitely not the reading that the writer of (61) had in mind.

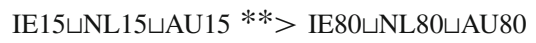

It is not specific to our analysis of comparatives that we predict weaker interpretations than the sentence seems to have. Consider the variant of our example in (73a). In this case again, the most salient interpretation is that each state economy improved between the mid-1980s and now. Using ** to cumulate on improve does derive this reading, but it also makes the sentence true in other scenarios, including the (unlikely) situation noted above. A similar result obtains for (73b), which relates two plural individuals (state economies and images).

(73) a. The state economies of Ireland, the Netherlands, and Australia improved their mid-1980s scores.

b. The state economies of Ireland, the Netherlands, and Australia improved their images.

A common solution to strengthening the cumulative reading is to restrict $* *$ by a pairrestrictor (cf. the paired-cover in Chap. 5 of Schwarzschild 1996), and we use it here. First, we have to modify the application of the cumulative operator, as follows: it does not apply directly to the relation $R$; it applies to $(R \cap \mathbf{P R})$, that is, the relation further restricted by $\mathbf{P R}$.

Second, we have to define PR, a pair-restrictor, as done in (74). ${ }^{10}$ Notice that this definition leaves relatively open which pairs will appear in PR. Schwarzschild (1996) argues at length that further specification is pragmatically driven and should be left open in the semantic definition.

$T$, a set of pairs, is a pair-restrictor (PR) (of the domain $D$ ) iff:

1. $T \subseteq D^{2}$

2. $\forall x \in D \exists y \in D[\langle x, y\rangle \in T]$

3. $\forall y \in D \exists x \in D[\langle x, y\rangle \in T]$

The example in (73a) should now be analysed as follows:

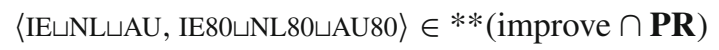

\footnotetext{
10 Schwarzschild (1996) uses a paired-cover, which restricts the members of pair-restrictors to the members of (unary) covers. This is needed in general, but not for our specific examples; hence we opted for a simplified definition to keep the discussion easier.
} 
We derive the most likely interpretation if we assume, following the idea of Schwarzschild (1996), that the PR by context and world knowledge has, among its members, pairs such as $\langle\mathrm{IE}, \mathrm{IE} 80\rangle,\langle\mathrm{NL}, \mathrm{NL80}\rangle,\langle\mathrm{AU}, \mathrm{AU} 80\rangle$, but not, crucially, elements like $\langle\mathrm{IE}, \mathrm{AU} 80\rangle$ etc. This derives that the state economies improved their own scores; however, it would be false if each economy improved compared to the economy of some other state in the mid-1980s. The same PR would correctly restrict the interpretation of (72), yielding the right truth conditions for (61) in our account.

But why should such PR be used here? Why would speakers consider these particular pair-restrictors and not others? Obviously, the first and the second element in the pairs of the most salient PR share more features (e.g., IE and IE80 involve the same state economy) than the pairs of less salient pair-restrictors. But matters are relatively complex here and not of immediate relevance to this article. ${ }^{11}$ What is relevant, however, is the conclusion that pragmatic restrictions are not specific to cumulative comparisons, and there is no reason to expect that the solution to such cases cannot be extended from plural individuals to plural degrees.

\section{Beyond universal quantifiers}

We have focused on the predictions that our analysis makes when than-clauses host distributive universal quantifiers. This contrasts with most research on comparatives, which studies how any quantifier (including modals) is interpreted in a than-clause. It turns out that our analysis makes similar predictions as Beck (2010) regarding the variation in the interpretation of other quantifiers. We briefly summarize the facts here.

A peculiar feature of the max-mechanism in Beck's framework is that in most cases, a than-clause like than $Q$ is/are tall will end up denoting the height of the tallest individual in the restrictor of Q. In other words, it appears that this mechanism rids the thanclause of any quantificational forces that it may contain and instead simply considers the set of entities (and, in particular, their heights) that partake in the quantification.

Downward monotone quantifiers are an exception to this. If the than-clause contains such a quantifier, the selection mechanism will always return an infinite degree. This, Beck argues, is a good result because it correctly explains why negative quantifiers are ungrammatical in than-clauses. A sentence like (76) can never be true (no degree is taller than the infinite degree).

*John is taller than no girl is.

This result carries over to our analysis, in which the than-clause of (76) is interpreted as follows:

$$
\lambda d . \neg \exists x[\operatorname{girl}(x) \wedge \mu(x) \sqsubseteq d]
$$

This gives us the set of all degrees other than the girls' heights (including all degrees exceeding the tallest girl's height). The application of $\min$ to this set will be undefined

11 See Chap. 5 of Schwarzschild (1996) for many examples on restrictions in paired-covers, and Chap. 3 of Dotlačil (2010) for the specification of some such restrictions in terms of the grouping principles uncovered in Gestalt psychology. 
since any degree aside from the girls' heights will satisfy (77), hence no minimal degree plurality can be found.

Its successes aside, there are two cases in which the selection mechanism misfires. The first problematic case is represented by modal quantifiers. Non-universal quantifiers (most prominently, indefinites and numerals) are the second.

We start with the first group. As background, note that some universal modal quantifiers behave as predicted (by Beck's and our analysis) and that we correctly derive the meaning of than-clauses with be supposed to and should. For example, assuming the background in (78) below, (78a) and (78b) will in our analysis mean that John's height exceeds the height of a male model in any world conforming to the stated conditions - in other words, that John is taller than $190 \mathrm{~cm}$.

(78) Background: John wants to become a model. Male models' height should be between $180 \mathrm{~cm}$ and $190 \mathrm{~cm}$.

a. John is taller than he is supposed to be.

b. John is taller than he should be.

However, the universal modals have to and be required to are problematic. The examples in (79) (might) convey in the same context that John's height exceeds $180 \mathrm{~cm}$. That is, the degree in the matrix clause has to exceed the minimal degree provided by the than-clause, not the maximal one. We don't derive this reading. To see this, recall that we let the degrees of the than-clause distribute over the matrix clause. This necessarily yields the reading that for every degree from $180 \mathrm{~cm}$ to $190 \mathrm{~cm}$, John exceeds that degree, i.e., John is taller than $190 \mathrm{~cm}$. The cumulative reading yields the same interpretation.

a. John is taller than he has to be.

b. John is taller than he is required to be.

We hasten to add a caveat. It has been noted repeatedly that the min-reading is more salient with the modals have to and be required to but the max-reading (John's height exceeds $190 \mathrm{~cm}$ ) is possible, too (Heim 2006; Krasikova 2008; Alrenga and Kennedy 2014). Two naturally occurring examples are given below. (80a), from the Corpus of Contemporary American English (COCA, Davies 2008), expresses the fear of a doctor in an emergency room that a seriously ill person will need to wait longer than he should (not that there is some minimally required time to stay in an emergency room and a seriously ill patient will wait longer than that). (80b), found using Google, ${ }^{12}$ says that the person exceeded his time to stay. These readings are straightforwardly derived in degree pluralities.

(80) a. I'm always afraid that somebody who's seriously ill has to wait longer than they have to for a physician.

b. He stayed longer than he had to even though he was told he had to leave(.)

\footnotetext{
12 http://www.revengeofthebirds.com/2011/6/13/2222685/the-arizona-cardinal-i-would-like-to-meetlarry-fitzgerald.
} 
That said, we would still need to explain where the salient minimal degree reading in examples like (79) comes from. We see two possible routes. First, we could retract our assumption that adjectives are inherently plural, and instead adopt the $\Pi$ operator as a means of lifting predicates of degrees to predicates of degree pluralities. As we briefly mentioned in Sect. 4, such an approach would predict scope ambiguities. For modal examples like (79), the than-clause interpretation looks either like (81a) or like (81b), yielding (82a) and (82b), respectively. (Compare to (38).)

$$
\begin{aligned}
& \text { a. }\left[\mathrm{WH}_{2}\left[\mathrm{MODAL}\left[\Pi \mathrm{t}_{2}\right]_{1}\left[\text { he }\left[\mathrm{be}\left[\mathrm{t}_{1} \text { tall }\right]\right]\right]\right]\right] \\
& \text { b. }\left[\mathrm{WH}_{2}\left[\Pi \mathrm{t}_{2}\right]_{1}\left[\mathrm{MODAL}\left[\text { he }\left[\mathrm{be}\left[\mathrm{t}_{1} \text { tall }\right]\right]\right]\right]\right. \\
& \text { a. } \lambda d \cdot \square[\mu(j) \sqsubseteq d] \\
& \text { b. } \lambda d \cdot \max \left(\lambda d^{\prime} . \square\left[\mu(j) \geq d^{\prime}\right]\right) \sqsubseteq d
\end{aligned}
$$

The interpretation in (82a) collects pluralities that contain at least all the atoms in the dense interval ranging from the minimally allowed height to the maximum. In the context of (78) above, that includes all the pluralities that contain at least all atoms between (and including) $180 \mathrm{~cm}$ and $190 \mathrm{~cm}$. The minimal plurality in that set is of course the dense plurality $180 \mathrm{~cm} \sqcup \ldots \sqcup 190 \mathrm{~cm}$ itself. Pluralising the comparative will then yield an interpretation for the sentences in (79) where John is taller than each of the atoms in this plurality, and so John is said to be too tall.

In contrast, the interpretation in (82b) is based on pluralities containing the atom $\max \left(\lambda d^{\prime} . \square\left[\mu(j) \geq d^{\prime}\right]\right)$, which is the minimum requirement for height. The minimal plurality is going to be the atomic degree that represents this minimum requirement, and so the sentences in (79) will now be interpreted as saying that John is more than sufficiently tall.

In order for an account along these lines to work, the scope of $\Pi$ would need to be restricted. First of all, modals like be supposed to and have to should always attach at a node higher than $\Pi$, since these modals only generate more-than-the-maximum readings. Second, $\Pi$ can never take scope over DPs either, since these also only generate more-than-the-maximum readings. It is hard to see where these restrictions come from.

The second route we could take follows Beck (2010) in taking up a suggestion made by Krasikova (2008) that the modals that give rise to the more-than-minimum reading are the same modals that occur in the so-called sufficiency modal constructions. An example of such a construction is given in (83). This sentence expresses that you don't have to do anything harder than going to the Twijnstraat to reach your goal of getting good cheese.

\section{You only have to go to the Twijnstraat (to get good cheese).}

Disregarding (difficult and unimportant) details, we can analyse only+have to as in (84a), where $q \subseteq p$ expresses the relevant ordering of propositions. In this case, the ordering would reflect how much effort one makes to get good cheese, i.e. how far one travels. Let us assume that the addressee of (83) is in Utrecht, and that there are various options, ranging from traveling to the closest place to traveling to the most remote place: to Janskerkhof (JK), to the Twijnstraat (TW), to the Haarlemmerstraat (HA), or to North End (NE). The propositions are ordered as NE $\subset \mathrm{HA} \subset \mathrm{TW} \subset \mathrm{JK}$. 
The sentence in (83) is true if the Twijnstraat is the nearest location to the addressee that sells good cheese.

$$
\begin{aligned}
& \text { a. } \llbracket \text { only have to } \rrbracket(p)=\square \cup\left\{p^{\prime} \mid p^{\prime} \in \text { Alt } \wedge p^{\prime} \subseteq p\right\} \wedge \\
& \neg \square \cup\left\{p^{\prime} \mid p^{\prime} \in A l t \wedge p^{\prime} \subset p\right\} \\
& \text { b. 【only have to } \rrbracket(\llbracket \text { you go to the Twijnstraat } \rrbracket) \\
& =\square(T W \vee H A \vee N E) \wedge \neg \square(H A \vee N E)
\end{aligned}
$$

Informally, only $+\square$ in (84a) is true of $p$ if and only if (i) in all worlds in which the goal is met, either $p$ or something higher on the scale is true; (ii) it is not the case that in all goal worlds, propositions higher in rank than $p$ are true. Using (84a), (84b) indeed reflects the correct interpretation.

Krasikova (2008) and Beck (2010) assume that the silent counterpart of only, EXH, appears in than-clauses that yield the min-reading. We follow their assumption, arriving at (85a) as the interpretation for than he has to be in (79). As in the previous example, we have to furthermore assume a particular ordering of alternatives, as Beck (2010) does. More concretely, the alternatives have to be ordered by height: tall(j,200) $\subset$ tall(j,190) $\subset$ tall(j,180) (for discussion of this assumption, see Beck (2010, pp. $36-37)) .{ }^{13}$ We can then rewrite (85a) in a more transparent way as (85b). Given the requirements on male models discussed above, (85) will yield only a singleton set, $\{180\}$ (John's minimal permissible height if he wants to become a model).

$$
\begin{array}{ll}
\text { a. } & \lambda d . \square \cup\left\{p^{\prime} \mid p^{\prime} \in \text { Alt } \wedge p^{\prime} \subseteq(\mu(j) \sqsubseteq d)\right\} \wedge \\
& \neg \square \cup\left\{p^{\prime} \mid p^{\prime} \in A l t \wedge p^{\prime} \subset(\mu(j) \sqsubseteq d)\right\} \\
\text { b. } & \lambda d . \square\left(\exists d^{\prime} \geq d\left[j^{\prime} \text { s height } \sqsubseteq d^{\prime}\right]\right) \wedge \neg \square\left(\exists d^{\prime}>d\left[j^{\prime} \text { s height } \sqsubseteq d^{\prime}\right]\right)
\end{array}
$$

Applying min to this set yields the only element, 180, and (79) is interpreted, correctly, to mean that John exceeds $180 \mathrm{~cm}$, the minimal requirement, not the maximal allowed height. Since the option of applying such EXH should only be open to the class of verbs that participate in sufficiency modal constructions, we now have an independent restriction for min-readings, which carves out the right class of modal verbs (see Krasikova 2008; Beck 2010 for discussion).

We now turn to the second potentially problematic class of examples that we inherit from adapting Beck's approach, viz. indefinites, numerals, and the like. Before we turn to the problems, we would first like to show that one type of indefinite-like quantification is handled properly in our analysis (and Beck's, for that matter; see Sect. 3). Referential indefinites are entirely unproblematic, as is shown in (86). (This naturally goes for any referential DP.)

a. John is taller than some (particular) friend of mine.

b. $\lambda d . f$ 's height $\sqsubseteq d$ where $f$ is the particular friend the speaker has in mind

\footnotetext{
13 There is another order of alternatives we have to postulate when pluralities enter the picture: they have to be ordered by the part-of relation. For example, tall(j,180 $181 \sqcup 182) \subset \operatorname{tall}(\mathrm{j}, 180 \sqcup 181) \subset \operatorname{tall}(\mathrm{j}, 180)$. This scale is easy to justify, as it follows entailment relations between propositions.
} 
But what happens if an indefinite is given a non-referential interpretation? Take, for example, (87) and assume one of his classmates is interpreted with narrow scope, non-referentially.

John is taller than one of his classmates is.

On Beck's approach, the than-clause would first collect the most informative intervals such that there exists a classmate whose height is in that interval. This yields the set of heights of the individual classmates. The second step in Beck's selection approach then picks the maximum degree from that set. As a result, Beck predicts (87) to have a more-than-maximum reading. She argues that this is a good result, since her intuitions tell her that certain German counterparts of (87) are ambiguous between a maximum and a referential reading. Our own intuitions are rather different. We think that both the Dutch and the Czech counterpart of (87) lack the more-than-maximum reading. It is beyond the scope of this paper to settle the empirical issue of which indefinites, if any, give rise to more-than-maximum readings in than-clauses. Interestingly, though, for better or for worse, the predictions of our approach actually differ from Beck's, just like our intuitions do. To see this, say that there are only two classmates; one is $170 \mathrm{~cm}$ tall and one $190 \mathrm{~cm}$. On our account, the than-clause of (87) would start out as returning those pluralities $d$ such that there exists a classmate of John's such that his or her height is included in $d$. Then, before the minimality operator applies, we have a set of pluralities some of which contain the degree 170 as an atomic part, some of which contain 190 as an atomic part, and some of which contain both. Applying min in (87), repeated below, now yields undefinedness, since there are two $d$ 's in this set that have no parts that are also in the set, namely the atoms 170 and 190.

$$
\begin{aligned}
& \text { Definition of } \min (\text { repeated): } \\
& \min \left(D_{\langle d, t\rangle}\right)=\iota d . d \in D \wedge \neg \exists d^{\prime}\left[d^{\prime} \in D \wedge d^{\prime} \sqsubset d\right]
\end{aligned}
$$

Up to now, all the examples we have looked at had than-clauses that collected a set of pluralities with a unique minimum. But as the above discussion shows, not all thanclauses provide such a unique minimal degree. Without amendment, our approach predicts that existential quantifiers in than-clauses yield undefinedness. In other words, indefinites can only be interpreted referentially.

For disjunction and any, where no referential readings are available, we reach the problematic prediction that they lack an interpretation in comparatives. This is clearly incorrect.

a. John is taller than Abby or Bill are.

b. $\min (\lambda d$.Abby's height $\sqsubseteq d \vee$ Bill's height $\sqsubseteq d)$ is undefined

a. John is taller than anyone else is.

b. $\min (\lambda d . \exists x(x \neq \operatorname{John} \wedge \mu(x) \sqsubseteq d))$ is undefined

In fact, it is not just existential quantifiers that create multiple minima. Any quantifier with multiple witnesses does so, and so any non-universal quantifier would yield undefinedness unless it is scoped out of the than-clause. Two examples would be (91a) and (91b). 
a. John is taller than exactly five girls are.

b. John is taller than most girls are.

For (91a), undefinedness can be avoided by following Beck in assuming that the nonmonotone quantifier can scope outside of the than-clause. This step yields (92), which is the correct interpretation. ${ }^{14}$

$$
\begin{aligned}
& \exists ! x_{\# 5}[\operatorname{girls}(x) \wedge \min (\lambda d . \forall y \leq x[\operatorname{Atom}(y) \rightarrow y \text { 's height } \sqsubseteq d]) \\
&\left.\in * \lambda d^{\prime} . \mu(j)>d^{\prime}\right]
\end{aligned}
$$

This analysis rests on the assumption that modified numerals are like indefinites in that they may escape scope islands. It is not very clear whether this assumption is warranted (Winter 1997). What is clear, though, is that such an analysis would not work for (91b): distributive quantifiers like most are definitely very faithful to scope islands. And if scoping out is not an option, our approach would predict (91b) to be uninterpretable. This is clearly a wrong prediction, and for that reason, we think that a slight modification of our minimality operator is warranted.

The idea is to substitute the iota operator with a choice function, which picks a random minimum degree from the set, as in (93). (The choice function is then existentially bound at the matrix level.)

$$
\begin{aligned}
& \text { Modified definition of min: } \\
& \min \left(D_{\langle d, t\rangle}\right)=f\left(\lambda d . d \in D \wedge \neg \exists d^{\prime}\left[d^{\prime} \in D \wedge d^{\prime} \sqsubset d\right]\right)
\end{aligned}
$$

This does not affect our analysis of universal quantifiers (and modals) because until the introduction of non-universals, the set of degrees of than-clauses always consisted of only one plurality. It leads to a slight modification of our explanation why negative quantifiers are banned from than-clauses, as in (76): this example now expresses that John is taller than some degree, which is totally uninformative. Most importantly, however, (93) has an effect on (87), since (93) effectively amounts to saying that nonuniversal quantifiers always yield a forced referential-like interpretation. The thanclause in (87) would now yield a single degree, the height of some classmate of John's. For (91a), we still have to require that the exhaustivity operator, forced by exactly, can scope at the matrix level, an assumption we share with negation approaches (Gajewski 2008; Alrenga and Kennedy 2014). However, unlike Beck (2010), we now can get rid of the wide scope of the quantifier itself. This is a positive result, given the reservations we expressed above with respect to the assumption that modified numerals have wide scope capabilities.

Definition (93) also makes correct predictions for (91b). In a nutshell, the approach predicts that this sentence says that John is taller than the tallest girl in some minimal witness to most girls. The weakest instance of that requirement is satisfied when John's

\footnotetext{
14 We make two simplifying assumptions in the notation: first, we assume that the whole quantifier undergoes QR into the matrix clause. A choice-functional approach, which is more standard with indefinites, would yield just the same results, as shown in Beck (2010). Second, we notate the "exactly" meaning using $\exists ! x_{\# 5}$, which is just an abbreviation for saying that five elements satisfy the scope, and no greater number does.
} 
height is compared to that majority of girls that contains only the shortest possible girls. And so the sentence is interpreted as John being taller than $50 \%$ of the girls.

Use of (93) would still misfire with disjunctions and indefinites like anyone, which would not have the observed max-readings in than-clauses (but rather than being undefined, as was the case before, they would now receive min-readings). It is conceivable that any gives rise to the max-reading by other means. Aloni and Roelofsen (2014) argue that any in than-clauses is interpreted as a free choice item, which would explain why it forces the same interpretation as universal quantifiers. We are not sure whether such an analysis could be extended to disjunction.

We are aware of one analysis which, we think, is particularly successful in assigning the correct interpretation to a wide range of quantifiers in than-clauses: the so-called 'no more analysis' by Alrenga and Kennedy (2014). It is therefore interesting to note that that analysis, while being clearly superior to ours and Beck's with respect to the cases discussed in the current section, does not seem to be capable of deriving the results that were the main topic of the rest of our paper. (See also Fleisher, to appear.) This is because the proposal in Alrenga and Kennedy (2014) is a sub-type of negation approaches, and just like other analyses in that tradition, their account destroys the information regarding individual degrees contributed by quantifiers in than-clauses. Narrowing the gap between our adaptation of Beck's selection strategy and the no more analysis will be an interesting task for the future.

\section{Conclusion}

In her 2006 paper, Heim slightly diverges from the interval theory of comparatives by letting adjectives like tall relate an individual and a set of degrees. The difference between her account and similar analyses, such as those of Schwarzschild and Wilkinson (2002) and Beck (2010), among others, is that the latter analyses impose an extra condition on arguments of adjectives: sets of degrees must be dense, that is, they must form an interval. But while Heim (2006) drops this restriction, she notes that no empirical facts drive this decision.

It is common to model pluralities as sets, and thus our paper can be seen as a defence of Heim's treatment of adjectives. In contrast to Heim (2006), however, we provided arguments that dropping the interval condition is a necessary step forward: the reformulation of an interval theory using degree pluralities allowed us to correctly analyse differentials (Sect. 5) and cumulative readings of comparatives (Sect. 6). Furthermore, these cases, we argued, are problematic for other accounts of comparatives. At the same time, the use of degree pluralities provides a comparable empirical coverage as Beck (2010) regarding the interpretations encountered for the full range of quantifiers in than-clauses of non-differential comparatives (Sect. 7).

Over the past three decades, the interpretation of the comparative has proven to be a remarkably difficult puzzle to solve. Progress has been steady, but slow. The reason for this is probably that the semantics of the comparative intersects a great number of phenomena, ranging from scalarity, ellipsis, and scope to (possibly) negation. As we have pointed out, part of the enigmatic nature of the semantics of -er may be 
explained by recognising that plurality is yet another phenomenon inherently tied to the comparative.

Acknowledgments The research leading to these results has received funding from the Netherlands Organisation for Scientific Research (NWO) VENI Grant 257.80.005 (Jakub Dotlačil) and VIDI Grant 276.70.017 (both authors) as well as from the European Research Council under the European Union's Seventh Framework Programme (FP/2007-2013) / ERC Grant Agreement no. 313502 (Rick Nouwen), which we hereby gratefully acknowledge. For discussion and comments, we would like to thank Sigrid Beck, Adrian Brasoveanu, Emmanuel Chemla, Nicholas Fleisher, Berit Gehrke, Nathan Klinedinst, Yaron McNabb, Philippe Schlenker, Benjamin Spector, and Yasutada Sudo, as well as audiences at the Workshop on (Co-)Distributivity at Paris 8 and local colloquia at J.W. Goethe Universität Frankfurt, UCL London, Radboud Universiteit Nijmegen, Universität Tübingen, and Universiteit Utrecht.

Open Access This article is distributed under the terms of the Creative Commons Attribution 4.0 International License (http://creativecommons.org/licenses/by/4.0/), which permits unrestricted use, distribution, and reproduction in any medium, provided you give appropriate credit to the original author(s) and the source, provide a link to the Creative Commons license, and indicate if changes were made.

\section{References}

Aloni, M., and F. Roelofsen. 2014. Indefinites in comparatives. Natural Language Semantics 22(2): 145167.

Alrenga, P., and C. Kennedy. 2014. No more shall we part: Quantifiers in English comparatives. Natural Language Semantics 22(1): 1-53.

Artstein, R., and N. Francez. 2003. Plural times and temporal modification. In Proceedings of the 14th Amsterdam Colloquium, ed. P. Dekker, and R. van Rooy, 63-68. Amsterdam: ILLC.

Beck, S. 2010. Quantifiers in than-clauses. Semantics \& Pragmatics 3: 1-72.

Beck, S. 2012. Lucinda driving too fast again: the scalar properties of ambiguous than-clauses. Journal of Semantics 29: 1-63.

Beck, S. 2014. Plural predication and quantifier 'than'-clauses. In The art and craft of semantics: A Festschrift for Irene Heim, ed. L. Crnic, and U. Sauerland. MITWPL 70, 91-115. Cambridge, Mass.: MIT.

Beck, S., and U. Sauerland. 2000. Cumulation is needed: A reply to Winter (2000). Natural Language Semantics 8(4): 349-371.

Beck, S., and Y. Sharvit. 2002. Pluralities of questions. Journal of Semantics 19(2): 105-157.

Bhatt, R., and R. Pancheva. 2004. Late merge of degree clauses. Linguistic Inquiry 35: 1-45.

Brasoveanu, A. 2008. Donkey pluralities: Plural information states versus non-atomic individuals. Linguistics and Philosophy 31(2): 129-209.

Bresnan, J. 1973. Syntax of the comparative clause construction in English. Linguistic Inquiry 4(3): 275343.

Carlson, G. 1977. Amount relatives. Language 53: 520-542.

Champollion, L. 2010a. Cumulative readings of every do not provide evidence for events and thematic roles. In Proceedings of the 17th Amsterdam Colloquium 2009, ed. M. Aloni, and K. Schulz. Amsterdam: Springer.

Champollion, L. 2010b. Parts of a whole: Distributivity as a bridge between aspect and measurement. Ph. D. thesis, University of Pennsylvania, Philadelphia.

Chomsky, N. 1977. On wh-movement. In Formal syntax, ed. P. Culicover, T. Wasow, and A. Akmajian, 71-132. New York: Academic Press.

Dalrymple, M., M. Kanazawa, S. Mchombo, and S. Peters. 1998. Reciprocal expressions and the concept of reciprocity. Linguistics and Philosophy 21: 159-210.

Davies, M. 2008. The corpus of contemporary american english (coca): 385 million words, 1990-present. http://www.americancorpus.org.

Dotlačil, J. 2010. Anaphora and distributivity: A study of same, different, reciprocals and others. Ph. D. thesis, LOT. 
Dowty, D.R., and B. Brodie. 1984. The semantics of "floated" quantifiers in a transformational grammar. In Proceedings of WCCFL 3, ed. M. Cobler, S. MacKaye, and M.T. Wescoat, 75-90. Stanford, CA: CSLI Publications.

Fintel, K. von, and S. Iatridou. 2005. What to do if you want to go to Harlem: Anankastic conditionals and related matters. Manuscript, MIT. http://web.mit.edu/fintel/www/harlem-rutgers.pdf.

Fitzgibbons, N., Y. Sharvit, and J. Gajewski. 2008. Plural superlatives and distributivity. In Proceedings of SALT 18, ed. T. Friedman and S. Ito, 302-318. Ithaca, N.Y.: CLC Publications.

Fleisher, N. (To appear). Comparing theories of quantifiers in than clauses: lessons from downward-entailing differentials. Semantics and Pragmatics.

Gajewski, J. 2008. More on quantifiers in comparative clauses. In Proceedings of SALT 18, ed. T. Friedman and S. Ito, 340-357. Ithaca, N.Y.: CLC Publications.

Gillon, B. 1987. The readings of plural noun phrases in English. Linguistics and Philosophy 10: 199-219.

Heim, I. 2000. Degree operators and scope. In Proceedings of SALT 10, ed. B. Jackson and T. Matthews, 40-64. Ithaca, N.Y.: CLC Publications.

Heim, I. 2006. Remarks on comparative clauses as generalized quantifiers. Manuscript, MIT. Online at http://semanticsarchive.net/Archive/mJiMDB1N/comparatives\%20as\%20GQs.

Heim, I., and A. Kratzer. 1998. Semantics in generative grammar. Oxford: Blackwell Publishing.

Hoeksema, J. 1983. Plurality and conjunction. In Studies in modeltheoretic semantics, ed. A. ter Meulen, 63-83. Dordrecht: Foris.

Hoeksema, J. 1996. Floating quantifiers, partitives and distributivity. In Partitives: Studies on the syntax and semantics of partitive and related constructions, ed. J. Hoeksema, 57-106. Berlin: Mouton de Gruyter.

Kennedy, C. 1997. Projecting the adjective: The syntax and semantics of gradability and comparison. PhD. Thesis, UC San Diego.

Kennedy, C. 2002. Comparative deletion and optimality in syntax. Natural Language \& Linguistic Theory 20(3): 553-621.

Krasikova, S. 2008. Quantifiers in comparatives. In Proceedings of SuB12, ed. A. Grønn, 337-352. Oslo: ILOS.

Kratzer, A. 2003. The event argument and the semantics of verbs. Manuscript, University of Massachusetts at Amherst; 4 chapters. http://semanticsarchive.net.

Krifka, M. 1989. Nominal reference, temporal constitution, and quantification in event semantics. In Semantics and contextual expressions, ed. R. Bartsch, J. van Benthem, and P. van Emde Boas, 75-115. Dordrecht: Foris.

Krifka, M. 1996. Parametrized sum individuals for plural reference and partitive quantification. Linguistics and Philosophy 19: 555-598.

Landman, F. 1989. Groups. Part I, II. Linguistics and Philosophy 12(559-605): 723-744.

Landman, F. 1996. Plurality. In The handbook of contemporary semantic theory, ed. S. Lappin, 425-457. Dordrecht: Blackwell.

Landman, F. 2000. Events and plurality. Dordrecht: Kluwer.

Larson, R. 1988. Scope and comparison. Linguistics and Philosophy 11: 1-26.

Lasersohn, P. 1998. Generalized distributivity operators. Linguistics and Philosophy 21(1): 83-93.

Link, G. 1983. The logical analysis of plurals and mass terms: a lattice- theoretical approach. In Meaning, use and interpretation of language, ed. R. Bäuerle, C. Schwarze, and A. von Stechow, 302-323. Berlin: de Gruyter.

Link, G. 1987. Generalised quantifiers and plurals. In Generalised quantifiers: Linguistic and logical approaches (Studies in linguistics and philosophy 31), ed. P. Gårdenfors, 151-180. Dordrecht: Reidel.

Matushansky, O., and E.G. Ruys. 2006. Meilleurs voeux: Quelques notes sur la comparaison plurielle. In Empirical issues in formal syntax and semantics 6, ed. O. Bonami and P.C. Hofherr, 309-330. Paris: Presses de l'Université de Paris-Sorbonne.

May, R. 1985. Logical form: Its structure and derivation. Cambridge, Mass.: MIT Press.

Nouwen, R. 2003. Complement anaphora and interpretation. Journal of Semantics 20(1): 73-113.

Nouwen, R. 2007. On dependent pronouns and dynamic semantics. Journal of Philosophical Logic 36(2): $123-154$.

Nouwen, R. 2015. Plurality. In Cambridge handbook of semantics, ed. M. Aloni and P. Dekker. Cambridge: Cambridge University Press. 
Reinhart, T. 1997. Quantifier scope: how labor is divided between QR and choice functions. Linguistics and Philosophy 20: 335-397.

Roberts, C. 1987. Modal Subordination, anaphora and distributivity. Ph. D. thesis, University of Massachussets, Amherst.

Scha, R., and D. Stallard 1988. Multi-level plurals and distributivity. In Proceedings of the 26th annual meeting of the ACL. 17-24. Morristown, N.J.: ACL.

Schein, B. 1993. Plurals and events (Current studies in linguistics 23). Cambridge, Mass.: MIT Press.

Schwarzschild, R. 1996. Pluralities. Dordrecht: Kluwer.

Schwarzschild, R. 2008. The semantics of comparatives and other degree constructions. Language and Linguistics Compass 2(2): 308-331.

Schwarzschild, R., and K. Wilkinson. 2002. Quantifiers in comparatives: A semantics of degree based on intervals. Natural Language Semantics 10: 1-41.

van den Berg, M. 1996. Some aspects of the internal structure of discourse: The dynamics of nominal anaphora. Ph. D. thesis, University of Amsterdam, Amsterdam.

van Rooij, R. 2008. Comparatives and quantifiers. In Empirical issues in syntax and semantics 7, ed. O. Bonami and P. Hofherr, 423-444. Paris: Presses de l'Université de Paris-Sorbonne.

von Stechow, A. 1984. Comparing semantic theories of comparison. Journal of Semantics 3: 1-77.

Winter, Y. 1997. Choice functions and the scopal semantics of indefinites. Linguistics and Philosophy 20: 399-467.

Winter, Y. 2000. Distributivity and dependency. Natural Language Semantics 8: 27-69.

Winter, Y. 2002. Atoms and sets: a characterization of semantic number. Linguistic Inquiry 33: 493-505. 